\title{
Dust resuspension under weak wind conditions: direct observations and model
}

\author{
O. G. Chkhetiani ${ }^{1,2}$, E. B. Gledzer ${ }^{1}$, M. S. Artamonova ${ }^{1}$, and M. A. Iordanskii ${ }^{3}$ \\ ${ }^{1}$ A.M.Obukhov Institute of Atmospheric Physics, Russian Academy of Sciences, Moscow, Russia \\ ${ }^{2}$ Space Research Institute, Russian Academy of Sciences, Moscow, Russia \\ ${ }^{3}$ State institution "Karpov Physics and Chemistry Institute”, Moscow, Russia \\ Correspondence to: O. G. Chkhetiani (ochkheti@rssi.ru)
}

Received: 13 July 2011 - Published in Atmos. Chem. Phys. Discuss.: 25 November 2011

Revised: 9 May 2012 - Accepted: 21 May 2012 - Published: 12 June 2012

\begin{abstract}
The results of direct observations of fine mineral dust aerosol $(0.15-15 \mu \mathrm{m})$ were carried out on extensive sand areas in desertificated lands of Kalmykia in 2007, 2009, and 2010 under conditions of weak wind and strong heating of the surface, almost in the absence of saltation processes. These results show that the fine mineral dust aerosol (0.15$0.5 \mu \mathrm{m})$ in the region under consideration contributes considerably to the total aerosol content of the atmospheric surface layer. Data on the mass concentrations of fine aerosol are treated on the basis of physical model estimates obtained for fluid dynamic parameters in the viscous thermal boundary layer near the ground surface. Deviations of these mass concentrations from their background values are related to a temperature drop in the thermal layer at the surface and from the values of friction velocity. For small and moderate values of friction velocity, these mass concentrations increase proportionally to a temperature drop with an exponent of about 0.5 , and, for high friction velocities, this exponent becomes negative $(\sim-0.5)$, which implies a decrease in these concentrations with an increase in a temperature drop.
\end{abstract}

\section{Introduction}

The underlying surface is a source of atmospheric mineral aerosols. The atmospheric dust is important for the formation of both regional and global climates (IPCC Fourth Assessment Report, IPCC IV, 2007). Present-day models of dust resuspension are based on wind saltation as the main mechanism for dust production. However, observations carried out in deserts clearly show the presence of mineral dust in the at- mosphere under windless and low-wind conditions (Golitsyn et al., 1997, 2003).

Experimental data and theoretical estimates show that particle detachment from the ground surface can be associated with turbulent stresses created by wind shear in the surface boundary layer. This mechanism occurs when the friction velocity $u_{*}=\left\langle-u^{\prime} v^{\prime}\right\rangle^{1 / 2}$ reaches a critical value of about $0.5 \mathrm{~m} \mathrm{~s}^{-1}$ (see Barenblatt and Golitsyn, 1974 and the references therein). The friction velocity $u_{*}$ is proportional to turbulent velocity fluctuations and determines the thickness $\delta_{*}$ of the viscous boundary layer at the (smooth) underlying surface: $\delta_{*} \approx 5 \frac{\nu}{u_{*}}$, where $v \approx 1.3 \times 10^{-5} \mathrm{~m}^{2} \mathrm{~s}^{-1}$ is the kinematic viscosity of air (Monin and Yaglom, 1971); for flows above water surface and other types of underlying surfaces with various roughness, some expressions of the numerical coefficients in the formula for the viscous sublayer thickness can be found in Foken $(1978,2008)$. For the indicated values of $u_{*}$, the value of $\delta_{*}$ is on the order of $100 \mu \mathrm{m}$. When $u_{*}$ reaches the critical values determined by the ground-surface and relief properties, particles whose size is larger than $\delta_{*}$ can be, depending on their mass and the degree of surface cohesion, pulled away from the viscous sublayer. Then, they are lifted by turbulent velocity fluctuations and participate in the saltation processes as one of the sources of fine aerosol fraction.

For controlled shear flows with large values of $u_{*}$, there are several sand flux formulas (beginning with the Bagnold's one $\sim u_{*}^{3}$, Bagnold, 1941) which depend on the friction velocity. Some of the approximations with the friction velocity threshold $u_{* c r}$ are described in Zhou et al. (2002); Kok and Renno (2009); Darmenova et al. (2009) (see also Shao, 2000). 
The situation is different when the size $D$ of dust particles is much smaller than $\delta_{*}(D \sim 0.1-10 \mu \mathrm{m})$. Such particles are completely immersed in the viscous sublayer, within which turbulent wind stresses decrease sharply and cannot overcome the particle cohesion. This situation is further complicated by the fact that, in reality, particles of these sizes are situated in cavities or pores between roughness elements formed by large-size particles or they form aggregate particles of various sizes. Nevertheless, experimental data suggest that even submicron dust particles are present in the atmosphere (Zhulanov et al., 1986; Golitsyn and Smirnov, 1993; Golitsyn et al., 1997, 2003).

There are several mechanisms proposed which explain this phenomenon. The most popular one is saltation (when particles with a size about $100 \mu \mathrm{m}$ are pulled away from the surface and then, fall back and knock out smaller particles) (Bagnold, 1941; Greeley and Iversen, 1985; Shao, 2000). The saltation is accompanied by sand bombardment with the further fracture of large particles and aggregate disintegration.

Various mechanical processes of submicron aerosol formation, such as rolling, breaking, severance and blowing were investigated in Kozlov et al. (2000). According to the estimates obtained in Kozlov et al. (2000), the mechanism of aerosol generation during sand interspersing may be considered as one of the sources of submicron aerosol in desert areas.

One more possible mechanism of dust emission is due to particle electrification (Yablokov and Andronova, 1997). Recently, this effect has been considered in detail in Kok and Renno (2006).

Dust emission related to the mesoscale circulation and convection in the atmospheric boundary layer was considered and analysed in Ponomarev (1998); Gorchakov et al. (2003); Cakmur et al. (2004); Takemi et al. (2006); Klose and Shao (2012); Marsham et al. (2008). It was shown that the total amount of dust emission due to these processes should not be neglected on longer timescales. On the whole, the specified mechanism occurs in addition to saltation in the presence of strong winds.

The saltation mechanism is directly associated with the effect exerted by fairly strong turbulent velocity fluctuations on average-size particles. This takes place only when the mean wind speed on the outer edge of the surface boundary layer exceeds a sufficiently large value of $\sim 10 \mathrm{~m} \mathrm{~s}^{-1}$. However, the number of atmospheric fine particles and the conditions for their occurrence suggest that they can also be lifted in calm weather, when the wind force is insufficient to form strong shear turbulence over the underlying surface.

For example, according to estimated characteristics of fine dust particles lifted in the atmospheric surface boundary layer of Mars, the wind speed must be such that $u_{*}$ is higher than $4 \mathrm{~m} \mathrm{~s}^{-1}$, which is not observed, while local dust storms are frequent events (Greeley and Iversen, 1985) (see Golitsyn, 1980; the kinematic viscosity for the Martian atmo- sphere is an order of magnitude and more larger than that for the Earth, so to get $\delta_{*} \approx 100 \mu \mathrm{m}$, the values of $u_{*}$ should be increased, see also Larsen et al., 2002).

Direct measurements of the concentrations of submicron aerosol $(0.1-1.0 \mu \mathrm{m})$ under desert conditions under low-wind conditions, when saltation processes calm down, are rare. Though there are data for particles of this size under the conditions of dust devil formation (Gillette and Sinclair, 1990; Gillette et al., 1993). Some observations of this aerosol fraction were carried out in the 1980s in Tajikistan during the expeditions exploring dust storms (Zhulanov et al., 1986; Golitsyn and Smirnov, 1993). Aerosols $(0.3-5.0 \mu \mathrm{m})$ were measured in the southern Taklamakan desert (Xinxiang province, China) (Mikami et al., 2005). The results of direct measurements of fine aerosol $(0.5-1.0 \mu \mathrm{m})$ during dust-plume events in the Qinghai province of China are given in Wang et al. (2010).

The results of laboratory measurements of the concentrations of dust particles up to $10 \mu \mathrm{m}$ during their resuspension in the absence of saltation are given in Loosmore and Hunt (2000); Gillette et al. (2004).

Most of the direct surface measurements of desert aerosol at the ground are, as a rule, performed at one level (height). Main attention was focused on the relations between aerosol concentrations and wind velocity or turbulence intensity (friction velocity).

In this study, we consider the situation with weak winds when it is necessary to find other mechanisms of dust emission in the absence of saltation. Under these conditions, strong convection of the air over the sand layer during hot weather is treated as the main mechanism of dust resuspension. So we intend to link dust mass concentrations to temperature drops in the thin surface air layer rather than to the amplitudes of velocity fluctuations in the turbulent boundary layer.

Similarly to pure shear turbulence with a viscous boundary layer of the thickness $\delta_{*}$ and with the characteristic fluctuation velocity $u_{*}$, the lift of sand and aerosol due to convective turbulence is determined by the thickness $\delta_{\mathrm{T}}$ of the convective boundary layer (in which the air temperature falls sharply with height) and by the characteristic convective horizontal velocity $u_{\mathrm{T}}$ at the outer boundary-layer edge.

Aerosol resuspension expressed in mass units (e.g., the aerosol mass concentration $\Delta C$, which is the difference between the mass concentrations at two levels - near the surface and above the thermal boundary layer) is found to be proportional to the velocity amplitude $u_{\mathrm{T}}: \Delta C \sim u_{\mathrm{T}}$.

The coefficient of proportionality depends on the properties of aerosol, soil, and ground relief. A more accurate dependence would be $\Delta C \sim u_{\mathrm{T}}-u_{\mathrm{T}}$ frr $u_{\mathrm{T}}>u_{\mathrm{T}}$, where $u_{\mathrm{T}}$ is the critical convective velocity below which there is no aerosol resuspension. For a strongly heated soil, $u_{\mathrm{T}}$ is higher than the critical value.

The 2007, 2009 and 2010 observational data on the concentrations of aerosol, including fine-size particles, for 
desertificated lands of Kalmykia under the conditions of light breeze and strong heating of soil (heat fluxes on a surface $f \sim 200-500 \mathrm{~W} \mathrm{~m}^{-2}$ ) are analyzed. It should be noted that these data were obtained almost in the absence of saltation on the sand surface $\left(u_{*}<0.5 \mathrm{~m} \mathrm{~s}^{-1}\right)$. The concentrations of aerosol at the surface (aerosol source) at a height of $0.5 \mathrm{~m}$ are compared to those at levels of 2 or $1.5 \mathrm{~m}$. At these latter heights, the concentrations of aerosol obtained under calmweather conditions are close to its background values.

In Sect. 2, we give a description of measurement sites, weather conditions and instruments. In Sect. 3, we present the results of particle and mass distributions and concentration variations with temperature drops at the soil surface and friction velocity. In Sect. 4, we present model estimates for convective motions and the dynamics of mass concentrations in the viscous thermal boundary layer at the heated soil surface, and these model estimates are compared with observational data. Summary and conclusions are presented in Sect. 5.

\section{Methods and materials}

\subsection{Measurements site}

Aerosol resuspension from the soil under calm-weather conditions was investigated during the 2007, 2009, and 2010 Kalmykian expeditions carried out in July. The republic of Kalmykia is located in the southeastern part of European Russia. In general, this region is a semidesert territory with extensive sandy areas covered by the ranges of dunes. There are also large dried-up and half-dried up salt lakes.

These observations were carried out at two sites (Fig. 1). One of them $\left(45^{\circ} 17^{\prime} 06^{\prime \prime} \mathrm{N} 45^{\circ} 53^{\prime} 12^{\prime \prime} \mathrm{E} ; 2007\right.$ and 2009) $700 \times 200 \mathrm{~m}$ in area was located at a distance of $20 \mathrm{~km}$ to the southwest of the Komsomolsky village. The other one $\left(45^{\circ} 25^{\prime} 52^{\prime \prime} \mathrm{N} 46^{\circ} 26^{\prime} 28^{\prime \prime} \mathrm{E}\right.$; 2010$) 1600 \times 600 \mathrm{~m}$ lies at a distance of $30 \mathrm{~km}$ to east of the Komsomolsky village. The observed sand areas had an area of $700 \times 200 \mathrm{~m}$ in 2007 , and an area of $1600 \times 600 \mathrm{~m}$ in 2009 , and was located at a distance of $30 \mathrm{~km}$ to the east of the Komsomolsky village. These sites were extended from northwest to southeast. Rare dunes less than $1.5 \mathrm{~m}$ in height were outside the measurement area. Such measurement area was chosen to reduce fetch effects, so that fine aerosol was emitted directly from the soil due to thermal or weak-wind forcing rather than to blowing off the tops of dunes and other ground elevations. Probably, the fetch effects on observational data cannot be completely eliminated, especially during strong wind gusts. The structure of the atmospheric boundary layer and processes related to arid aerosol emission were measured simultaneously.

Receiving notebook computers and Data Loggers of all measuring devices were in small mobile boxing $50 \mathrm{~m}$ away from the measurements site with consideration for a domi- nating wind direction. All used devices are synchronized by the GPS means.

\subsubsection{Aerosol measurements}

The concentration and size distribution of aerosol particles were measured in the daytime (usually from 09:00 to 19:00) at two levels: $0.5 \mathrm{~m}$ and $2.0 \mathrm{~m}$ (in 2007 and 2010) and $0.5 \mathrm{~m}$ and $1.5 \mathrm{~m}$ (2009) with Laser Aerosol Spectrometer (LASPC) (model 9814.290.000 designed and made at Karpov Physics and Chemistry Institute, which had certification) and a Royco Optical Particle Counter, Model 220 (Royco Instrument, Inc., Menlo Park, Calif.).

The LAS-PC aerosol spectrometer allows the determination of the size distribution of particles ranging from 0.15 to $1.5 \mu \mathrm{m}$ in media characterized by particle concentrations up to $2 \times 10^{3} \mathrm{~cm}^{-3}$. The maximum relative errors in determining the volume of air samples and the size of particles and their concentration amount to $\pm 5 \%$ and $\pm 10 \%$, respectively. The maximum relative errors in determining the volume of air samples and the size of particles and their concentration amount $0.15-0.2,0.2-0.25,0.25-0.3,0.3-0.4,0.4-0.5,0.5-$ $0.7,0.7-1.0,1.0-1.5,>1.5 \mu \mathrm{m}$.

The Royco (Model 220) aerosol spectrometer allows the determination of the size distribution of particles ranging from 0.5 to $15 \mu \mathrm{m}$. The Royco (Model 220) aerosol spectrometer allows the determination of the size distribution of particles ranging from $\pm 5 \%$ and $\pm 10 \%$, respectively. The particle size is measured with an error of $\pm 5 \%$. The multichannel size distribution had the following size ranges: $0.5-$ 0.7, 0.7-1.0, 1.0-1.5, 1.5-2.0, 2.0-3.0, 3.0-5.0, 5.0-7.0, 7.0$10.0,10.0-15.0,>15.0 \mu \mathrm{m}$.

The unified set of instrumentation operated automatically and was interfaced with a notebook computer. Air samples for determining the aerosol composition were taken through the teflon tubes 3-4 m long separately for each counter.

The aerosol counters used for the observation were calibrated on canals by monodispersed polystyrene latex particles. Before and after each expedition, the counters were exposed to a special cleaning from dust. During field measurements, every day these counters were checked out using an interior calibrator. Taking into account a small aerosol flux under the conditions of light winds, data on particle concentrations are recorded with one-minute intervals.

\subsubsection{Weather conditions}

The daytime wind speed, air temperature, and humidity at levels of $0.2,0.5,1.0,2.0,3.0$, and $5.0 \mathrm{~m}$ were continuously measured. Additionally, the temperature and humidity of the surface were measured with five sensors placed around the base of aerosol counters approximately at a distance of 1$2 \mathrm{~m}$. The ground surface sensors were covered with a very thin sand layer to reduce direct radiation effects. Under clear sky, the surface temperature of the sand was $60-70^{\circ} \mathrm{C}$. At 


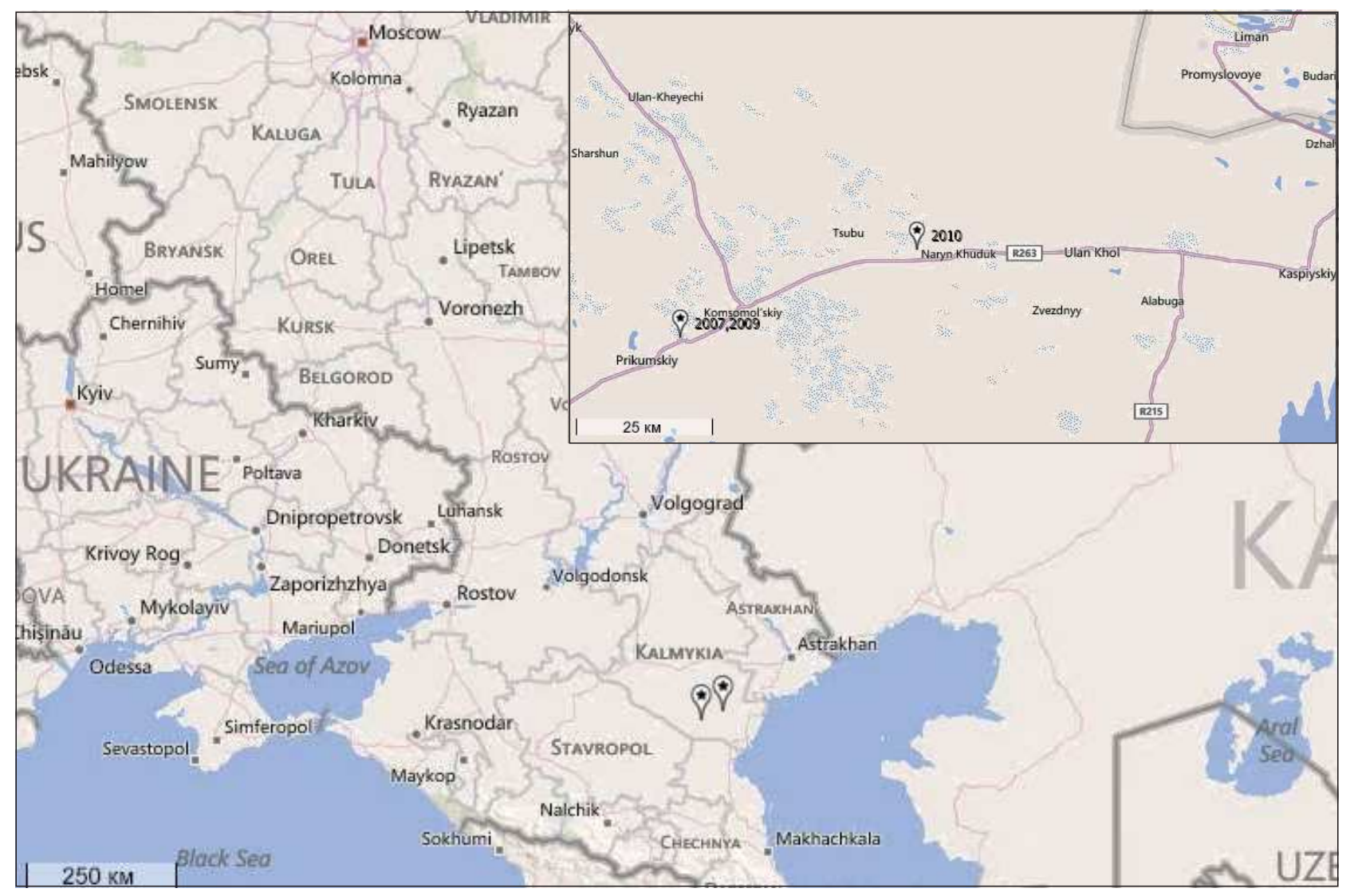

Fig. 1. Location of sites during the 2007, 2009, and 2010 Kalmykian expeditions.

the same time, the air temperature at a level of $3 \mathrm{~m}$ was about $40{ }^{\circ} \mathrm{C}$ and the wind speed at $2 \mathrm{~m}$ ranged from $1.7 \mathrm{~m}$ to $5.5 \mathrm{~m} \mathrm{~s}^{-1}$. The daytime heat fluxes varied from 200 to $350 \mathrm{~W} \mathrm{~m}^{-2}$ with spikes up to $500 \mathrm{~W} \mathrm{~m}^{-2}$.

In 2009 and 2010 we used two-level measurements of meteorological parameters (air temperature, horizontal wind, wind direction, air pressure and air humidity) at heights of 2 and $10 \mathrm{~m}$. The measuring complex was constructed on the basis of AANDERAA Data Instruments' sensors. Additionally, at a height of $2 \mathrm{~m}$, fluctuations in three wind-velocity components and air temperature were measured with an USA-1 (METEK).

The friction velocity was calculated according to the Monin-Oboukhov theory from the velocity differences at different levels $(0.5 \mathrm{~m}$ and $2 \mathrm{~m}$ in $2007 ; 2 \mathrm{~m}$ and $10 \mathrm{~m}$ in 2009,2010 ) and amounted to $0.05-0.5 \mathrm{~m} \mathrm{~s}^{-1}$. In this work, we used a simpler version of determining $u_{*}$ determination. We calculated $u_{*}$ from the measured mean horizontal velocity $u(z)$ at the height $z=3 \mathrm{~m}$ by using the formula $u_{*}=$ $\kappa u(z) / \ln \left(z / z_{0}\right)$, where $z_{0}=10^{-4} \mathrm{~m}$ and $\kappa=0.4$ (von Karman constant). This simple formula yields satisfactory estimates of the intensity of turbulent fluctuations in the boundary layer and does not require additional assumptions.

\section{Results}

\subsection{Particles and mass distributions}

The distributions of aerosol particles are given for 2007 Fig. 2a, c and 2009 Fig. 2b, d. Figure 2a, b represents the daytime mean distrubutions of aerosol particles at height $2 \mathrm{~m}$ (2007) and $1.5 \mathrm{~m}$ (2009). Figure $2 \mathrm{c}$, d shows the mass concentrations of aerosol particles with respect to their size. The mass distributions $\Delta M / \Delta \log (d)$ were calculated according to the technique described in Junge (1963), which roughly correspond (with accuracy up to constants) to the function $d^{3} \Delta N / \Delta \log (d)$. It is well seen that the basic aerosol mass is concentrated on small scaled particles on days with moderate wind, while large size particles appear at stronger wind $V(2)>4.8 \mathrm{~m} \mathrm{~s}^{-1}(V(2)$ is the daytime-averaged horizontal velocity at a height $2 \mathrm{~m}$ ), for measurements in 2007 and $V(2.2)>4.0 \mathrm{~m} \mathrm{~s}^{-1}$ for measurements in 2009. Figure 2a, b shows that the fraction of submicron particles considerably exceeds in number the fraction of particles with sizes more than $1 \mu \mathrm{m}$. Even in terms of mass (Fig. 2c, d), the fraction of $0.1-0.6-\mu \mathrm{m}$ particles is comparable to that of $0.6-8-\mu \mathrm{m}$ particles. In fact, the observation conditions were stable from 28 to 31 July 2007 . The same conditions were observed for 

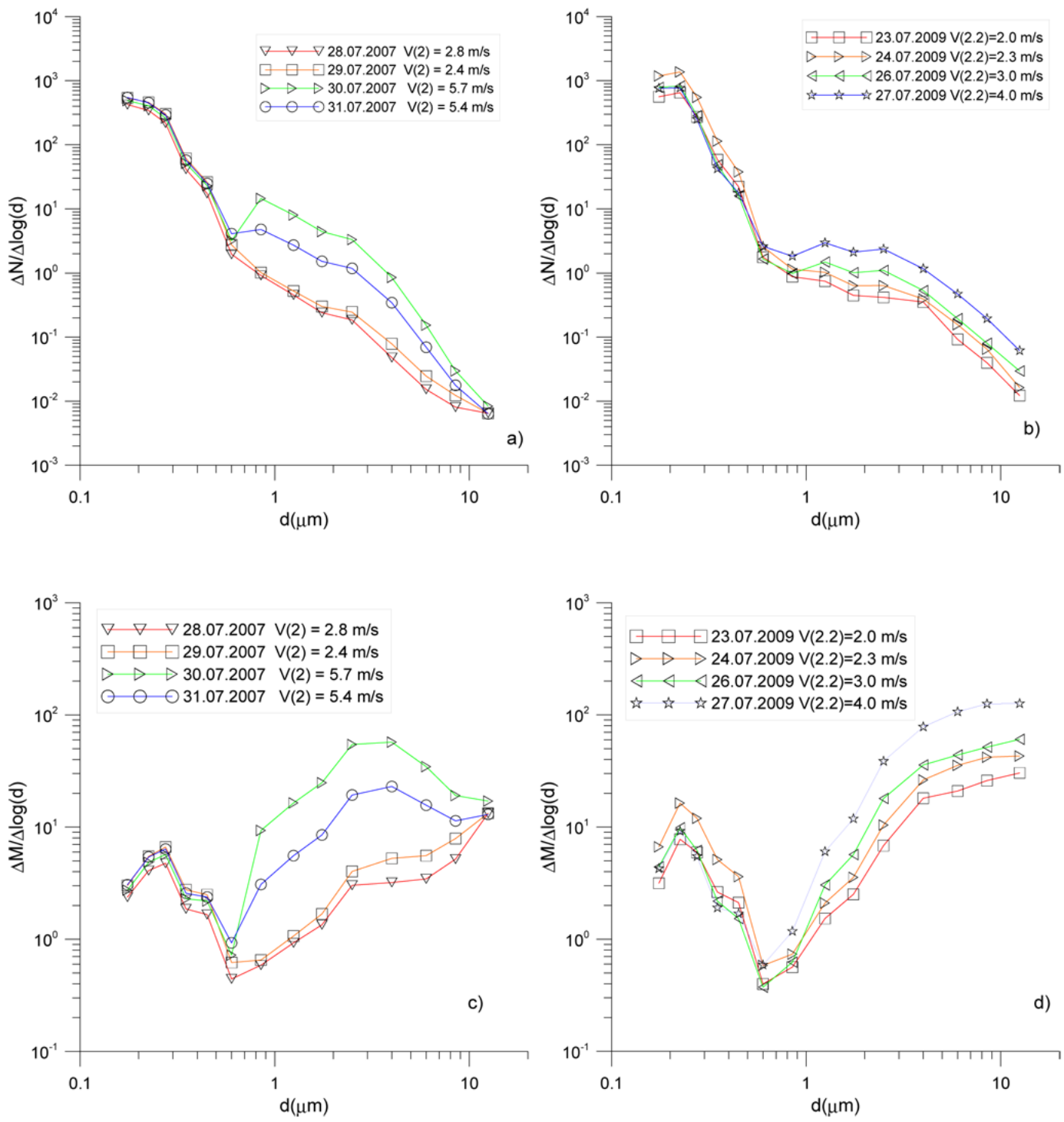

Fig. 2. Daytime mean distributions of particles at a height of $2 \mathrm{~m}$ (a) for 2007, (b) for 2009; inserts: the daytime-mean horizontal velocity at $2 \mathrm{~m}$ (for 2007) and $2.2 \mathrm{~m}$ (for 2009). Daytime-mean mass distribution of particles at $2 \mathrm{~m}$ (c) for 2007, (d) for 2009); inserts: the daytimeaveraged horizontal velocity at $2 \mathrm{~m}$ (for 2007) and $2.2 \mathrm{~m}$ (for 2009).

23-27 July 2009 and 19 and 27 July 2010 (with weak winds in the morning and moderate winds in the afternoon). In Borrmann and Jaenicke (1987), it was shown that particles with diameter from 0.71 to $1.01 \mu \mathrm{m}$ are the lower limit for aerosol knocked out by grains of sand.

The similar behaviour of the distribution function was also observed in other desert aerosol field experiments (Zhulanov et al., 1986; Golitsyn and Smirnov, 1993; Kandler et al., 2009; Weinzierl et al., 2009).

\subsection{Variations in the number and mass concentration of particles under different weather conditions}

In this subsection we consider the relationships between the concentration differences and temperature drops in the viscous thermal boundary layer and friction velocities.

\subsubsection{Small and moderate friction velocities}

It follows from the estimates given below that convection is determined by temperature differences in this layer, for example, by the difference $\delta T$ between the ground surface temperature $T_{\mathrm{s}}$ and the air temperature $T_{0.2}$ at $0.2 \mathrm{~m}$. In Fig. 3 the temperature difference $\delta T=T_{\mathrm{s}}-T_{0.2}$ is shown as 

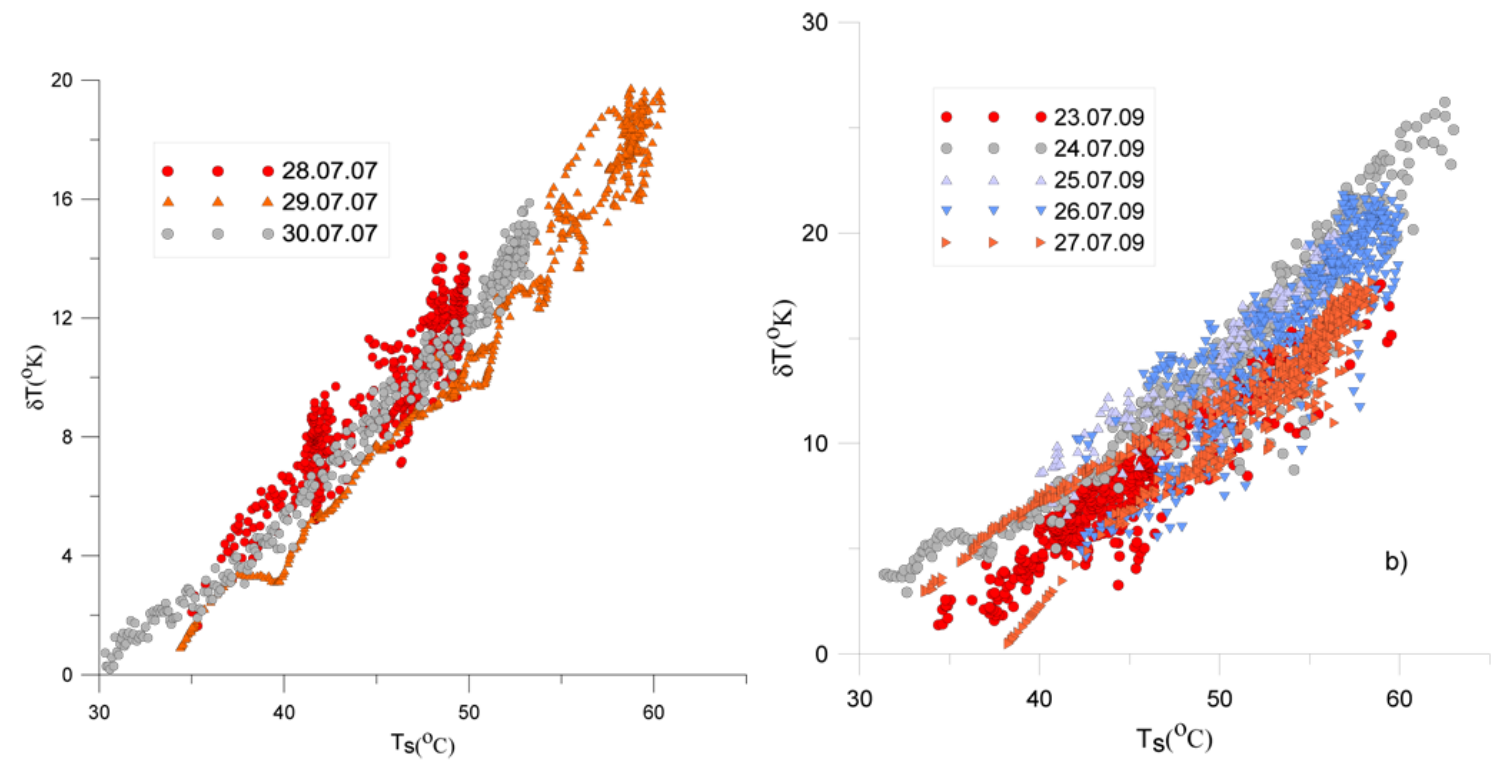

Fig. 3. The temperature difference $\delta T$ between the ground surface temperature $T_{\mathrm{S}}\left({ }^{\circ} \mathrm{C}\right)$ and the air temperature at $0.2 \mathrm{~m}$ : (a) $($ data of $28-$ 30 July 2007), (b) (data of 23-27 July 2009).

a dependence on $T_{\mathrm{s}}$ for the conditions with relatively light wind. We see practically a linear dependence for all surface temperature values. For the surface temperature $T_{\mathrm{S}}$ less than $31-33{ }^{\circ} \mathrm{C}$ the difference $\delta T$ is, on average, almost zero. This means that, when the ground temperature does not differ significantly from the temperature of the ambient air, turbulent mixing near the surface smoothes vertical temperature variations in the air surface layer.

In Fig. 4 the vertical axes represent the deviations of the aerosol mass concentration values $\left(\mu \mathrm{g} \mathrm{m}^{-3}\right)$ for particles $0.15-0.5 \mu \mathrm{m}$ in size (2007) and $0.15-1.0 \mu \mathrm{m}$ (2009). The vertical axes represent the deviations of the aerosol mass concentration values $\delta T$ between the ground surface and the height $0.2 \mathrm{~m}$ for conditions of relatively light wind (Fig. $4 \mathrm{a}, \mathrm{b}$ for 2007, Fig. 4c, d for 2009). These concentrations were obtained integrating data recorded in the LAS-PC canals (5 channels for particles $0.15-0.5 \mu \mathrm{m}$ and 8 channels for particles $0.15-1.0 \mu \mathrm{m})$.

The winds shown in the inserts of Fig. 2 are the average velocities at heights of $2 \mathrm{~m}$ (2007) and $2.2 \mathrm{~m}$ (2009). The circles in Fig. 4 depict the values of $\Delta C, \delta T$ derived from concentrations measured for $1 \mathrm{~min}$ (the time required for the intake of air with aerosol in LAS-Pc and Royco OPC).

The mass concentration was recalculated from the LASPC measured particle concentrations using the mean particle size for a given channel. For a given value of $\delta T$, a scatter in points corresponds to different values of $u_{*}$. However, if the variance of $u_{*}$ for different fixed $\delta T$ is identical, then the width of the scatter area is also nearly identical for different $\delta T$. In Figs. 4, 6, and 7 the smooth line corresponds to data approximation by the power law $\Delta C \sim(\delta T)^{\alpha}$. For moderate values of $u_{*}\left(u_{*}<0.3 \mathrm{~m} \mathrm{~s}^{-1}\right)$ in Fig. 4 , the exponent $\alpha$ amounts to $\alpha \approx 0.58$ (Fig. 4a), 0.52 (Fig. 4b), 0.33 (Fig. 4c), and 0.24 (Fig. 4c).

The concentrations $C(2.0), C(1.5)$ are regarded conditionally as the "background" values. As was noted above, the measurement conditions were chosen so that the influence of aerosol resuspension from the dunes surrounding the measurement site was minimal. However, even in this case, the concentrations $C(2.0)$ and $C(1.5)$ cannot be regarded as absolute background values since they vary from day to day, and depend on air humidity, temperature, and wind over a time period preceding the measurements.

It follows from the figures above that the differences in $\Delta C$ for 2009 exceed several times those for 2007; this reflects various weather conditions for measurements in these years, in particular, lighter breezes in 2009 promoted aerosol accumulation in the surface air layer.

Therefore, $C(2.0)$ and $C(1.5)$ can be formally considered as background concentrations for several hours of daytime measurements. This is demonstrated in Fig. 5, which display the mass concentrations $C(0.5)$ and $C(2.0)$ (or $C(1.5)$ ) for particles $0.15-0.5 \mu \mathrm{m}(0.15-1.0 \mu \mathrm{m})$ as a functions of the temperature differences $\delta T$ between the ground surface and the height $0.2 \mathrm{~m}$ for data of 29 and 30 July $2007(\mathrm{a}, \mathrm{b})$ and 23 July p.m. and 24 a.m. 2009 (c, d) for different wind conditions: for (a) $V(2) \approx 2.4 \mathrm{~m} \mathrm{~s}^{-1}$, for (b) $V(2) \approx 5.7 \mathrm{~m} \mathrm{~s}^{-1}$, for (c) $V(2.2) \approx 2.0 \mathrm{~m} \mathrm{~s}^{-1}$ (morning), for (d) $V(2.2) \approx$ $2.8 \mathrm{~m} \mathrm{~s}^{-1}$ (afternoon). Inspection of Fig. 5 shows that the values of $C(2.0)$ (for 2007) lie approximately in the range of $1.5-2 \mu \mathrm{g} \mathrm{m}^{-3}$ and $C(1.5)$ for 2009 in the range $3 \mu \mathrm{g} \mathrm{m}^{-3}$ (for 23 July p.m.) and $5 \mu \mathrm{g} \mathrm{m}^{-3}$ (for 24 July a.m.). Moreover, the values of $C(0.5)$ widely vary with an increase in wind velocity (Fig. 5d). 

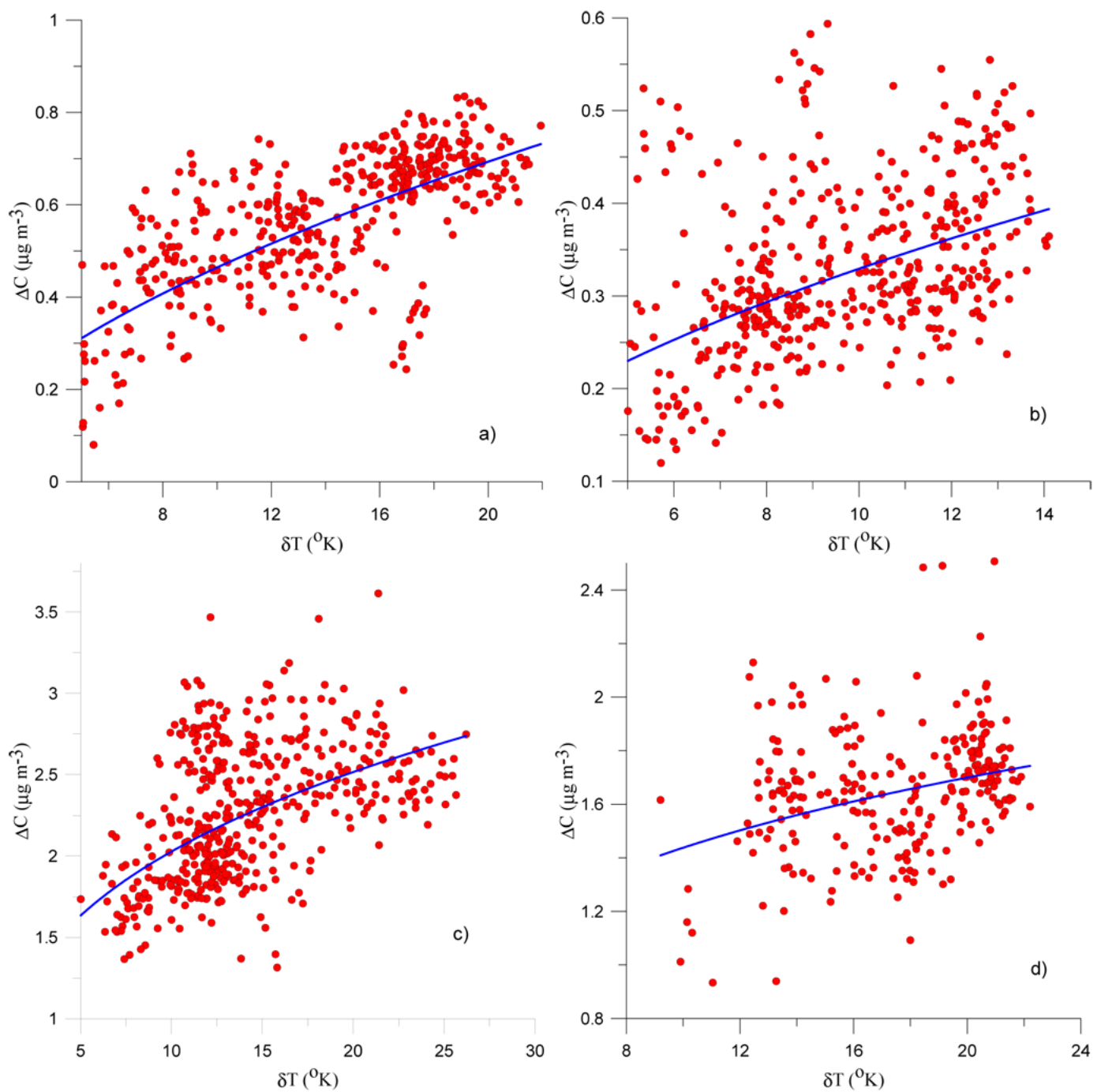

Fig. 4. Deviations of the aerosol mass concentrations recorded at a height of $0.5 \mathrm{~m}$ from those recorded at a height of 2-m (for 2007) and 1.5-m (for 2009) $\left(\mu \mathrm{g} \mathrm{m}^{-3}\right.$ ) for particles $0.15-0.5 \mu \mathrm{m}$ in size (for 2007) and 0.15-1.0 $\mu \mathrm{m}$ (for 2009) as a function of the temperature difference $\delta T$ between the ground surface and $0.2 \mathrm{~m}$. (a) data of $29 \mathrm{July} 2007$; the 2-m daytime averaged wind speed is $2.4 \mathrm{~m} \mathrm{~s}{ }^{-1}$, and $u_{*}<0.2 \mathrm{~m} \mathrm{~s}^{-1}$; the smooth line corresponds to the approximation $\Delta C \sim \delta T^{0.58}$; (b) data of $28 \mathrm{July} 2007$; the 2-m wind speed is $2.8 \mathrm{~m} \mathrm{~s}{ }^{-1}$, and $u_{*}<0.3 \mathrm{~m} \mathrm{~s}^{-1}$; the smooth line denotes $\Delta C \sim \delta T^{0.52}$; (c) data of 24 July a.m. 2009; the 2.2-m wind speed is $2.0 \mathrm{~m} \mathrm{~s}^{-1}$ (in the morning), and $u_{*}<0.2 \mathrm{~m} \mathrm{~s}^{-1}$; the smooth line $-\Delta C \sim \delta T^{0.33}$; (d) data of 26 July a.m. 2009; the 2.2-m wind speed is $3.0 \mathrm{~m} \mathrm{~s}^{-1}$, and $u_{*}<0.3 \mathrm{~m} \mathrm{~s}{ }^{-1}$; the smooth line denotes $\Delta C \sim \delta T^{0.24}$.

\subsubsection{High friction velocities}

For relative strong winds the deviations $\Delta C$ of mass concentrations are shown in Fig. 6a (for 30, 31 July 2007) and Fig. $6 b$ (for 26 July p.m. 2009). For these days with sufficiently high $u_{*}\left(u_{*} \approx 0.3-0.4 \mathrm{~m} \mathrm{~s}^{-1}\right)$, the exponent $\alpha$ is negative $(\alpha \approx-0.50$ in Fig. 6 a, data of 30 July $2007 ;-0.35$ in Fig. 6a, data of 31 July $2007 ;-0.35$ in Fig. 6b, data of 26 July p.m. 2009). For such values of $u_{*}$, deviations of aerosol mass concentrations decrease with an increase in $\delta T$.

The noted dependence on the friction velocity $u_{*}$ (or the wind speed $u(z))$ is differently manifested. On the one hand, the exponent $\alpha$ changes its sign with an increase in friction velocity. On the other hand, for a specified $\delta T$ (for example, $\delta T=10 K$ ), with an increase in $u_{*} \Delta C$ increases twofour times (going from Fig. 4a to 6a or Fig. 5a to b). Thus, the possible approximation $\Delta C=\Delta C\left(u_{*}, \delta T\right)$ would give strong dependence on $u_{*}$. Unfortunately, empirical data are too scarce to construct such functions.

The difference between the morning and afternoon wind conditions can significantly change the variance of the deviations $\Delta C$ with temperature $\delta T$ increasing. This is illustrated in Fig. 7a, b for the same day of 27 July 2009. The similar behavior of $\Delta C$ was also observed for 23 July (afternoon), 

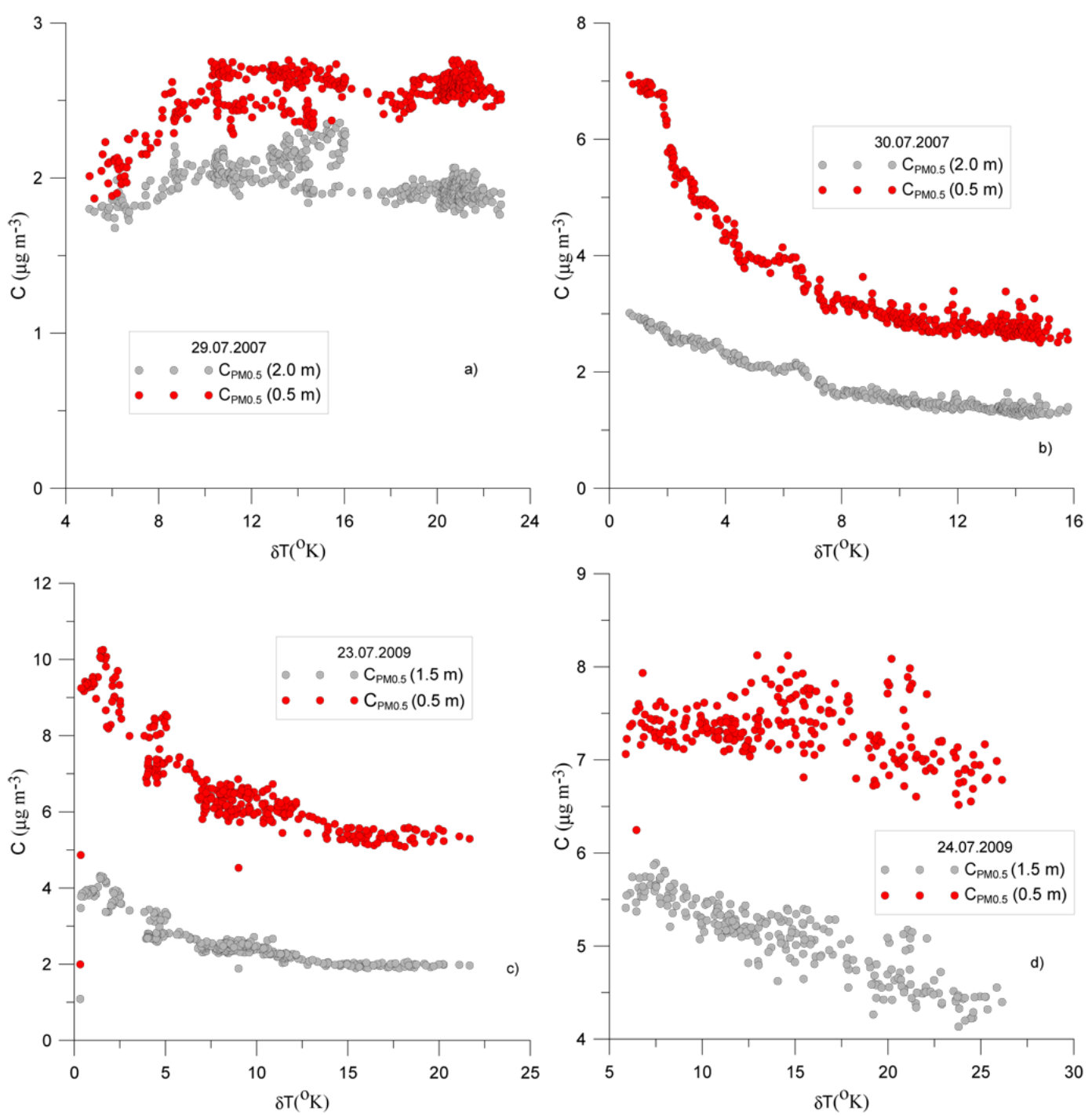

Fig. 5. Mass concentrations at heights of $0.5 \mathrm{~m} C(0.5)$ and $2 \mathrm{~m} C(2.0)$ for (a, b), $1.5 \mathrm{~m} C(1.5)$ for (c, d) ( $\mu \mathrm{g} \mathrm{m}^{-3}$ ) for particles $0.15-0.5 \mu \mathrm{m}$ in size and the temperature difference $\delta T$ between the ground surface and $0.2 \mathrm{~m}$ : (a) for $29 \mathrm{July} 2007$, (b) for $30 \mathrm{July} 2007$, (c) for $23 \mathrm{July}$ p.m. 2009, (d) for 24 July a.m. 2009.

2009. The results for 27 and 19 July 2010 are in Fig. 7c, d for weak and moderate values of wind.

Note that the value of $\delta T$ in Figs. 4-6 decreases with increasing $u_{*}$ (going from Fig. 4a to 6a or Fig. 5a to b). Obviously, this reflects the fact that a heated surface is cooled better when the wind velocity increases (turbulent mixing in the layer). This is illustrated in Fig. 8 for small and moderate values of $u_{*}$.

Below, we will discuss the observed dependencies of aerosol concentrations on temperature drops on the basis of estimates obtained from the main terms of the BoussinesqOberbeck equations, which describe convection in a viscous thermal boundary layer at the heated soil surface.

\section{Motions in a convective viscous surface layer}

The results of temperature measurements show that the air over the sand surface is in convective motion due to the heating of the layer up to temperatures of $\sim 40-70{ }^{\circ} \mathrm{C}$ (Golitsyn et al., 2003). In the air layer $\sim 0.5-1 \mathrm{~mm}$ thick, the temperature falls sharply with height (by about $10-30^{\circ} \mathrm{K}$ ). Moreover, this fall occurs mainly within a centimeter air layer over the sand surface.

Consider the motion of air at the boundary $z=0$ of a heated soil layer. The convective layer under study is on the order of $1 \mathrm{~cm}$ thick. The temperature within it falls with height by $\sim 10-30{ }^{\circ} \mathrm{C}$ from $40-70^{\circ} \mathrm{C}$ on the sand surface. Several formulas describing developed free convection in a layer heated from below can be found in Golitsyn (1980). 

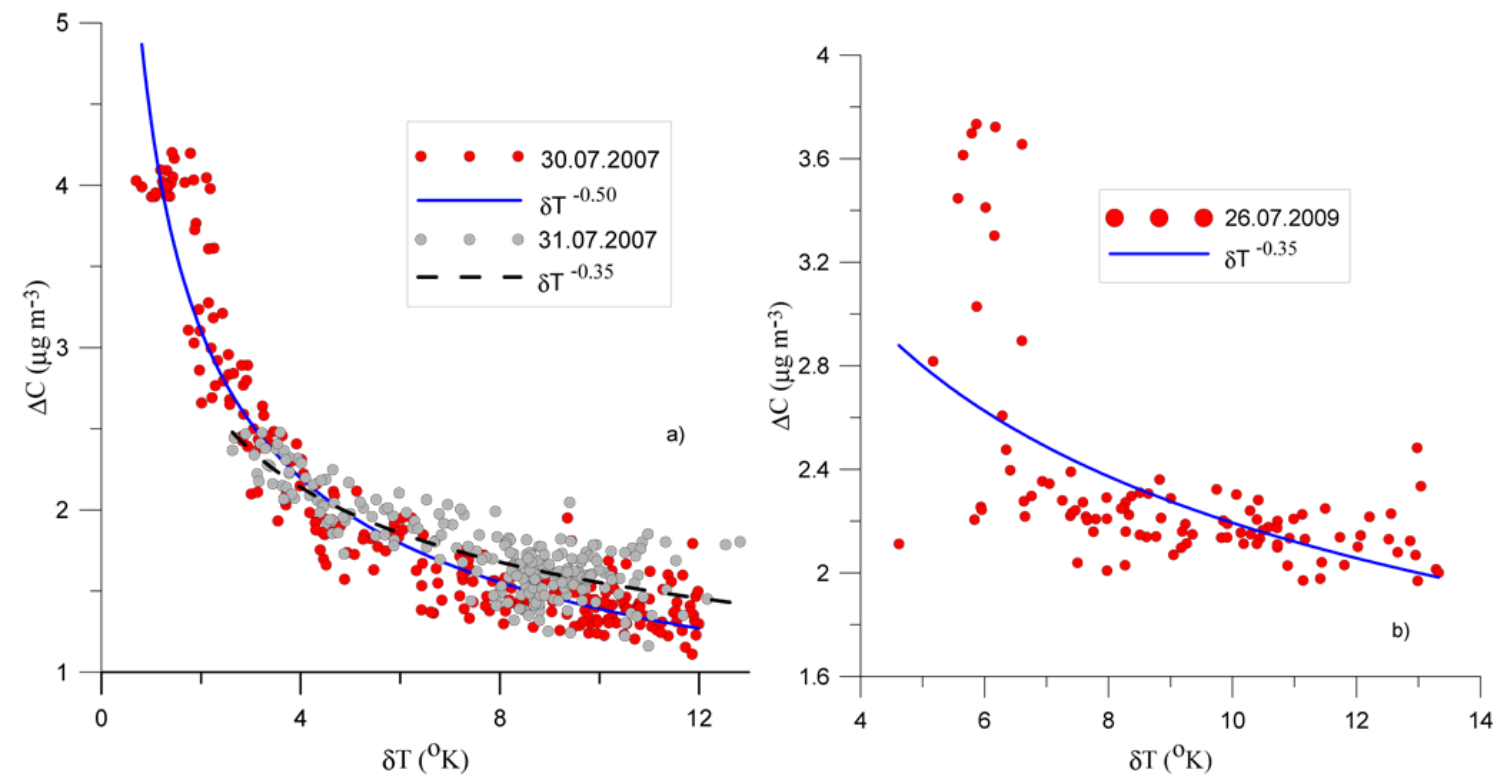

Fig. 6. Deviations of the aerosol mass concentrations obtained at a height $0.5 \mathrm{~m}$ from the $2-\mathrm{m}$ values (for 2007) and $1.5-\mathrm{m}$ (for 2009$)\left(\mu \mathrm{g} \mathrm{m}^{-3}\right.$ ) for particles $0.15-0.5 \mu \mathrm{m}$ in size as functions of the temperature difference $\delta T$ between the ground surface and $0.2 \mathrm{~m}$; (a) the 2-m daytime averaged wind speed is $5.7 \mathrm{~m} \mathrm{~s}^{-1}$ for 30 July 2007 , and $5.4 \mathrm{~m} \mathrm{~s}^{-1}$ for $31 \mathrm{July} 2007$, the solid line depicts the approximation $\Delta C \sim \delta T^{-0.5}$ for 30 July 2007 and the dashed line corresponds $\Delta C \sim \delta T^{-0.35}$ for 31 July 2007; (b) the 2.2-m wind speed is $3.0 \mathrm{~m} \mathrm{~s}^{-1}$ for 26 July p.m. 2009, the solid line depicts $\Delta C \sim \delta T^{-0.35}$.

They are developments of Oboukhov's (1946) and MoninOboukhov's (1954) theories presented in Obukhov (1971); Lumley and Panofsky (1964) (for more full and recent references see Foken, 2008), and expressions are given for the thickness $\delta_{\mathrm{T}}$ of the boundary layer, in which the temperature decreases by $\delta T$ (see Golitsyn, 1980):

$\delta_{\mathrm{T}} \approx \frac{l_{v}}{2 \beta_{1} \operatorname{Pr}^{1 / 3}}\left(\frac{T_{0}}{\delta T}\right)^{1 / 3}$,

where $l_{v}=\left(v^{2} / g\right)^{1 / 3}, \operatorname{Pr}=v / \kappa_{\mathrm{T}}$.

Above, $v$ is the kinematic viscosity and $\kappa_{\mathrm{T}}$ is the thermal diffusivity. $T_{0}$ is the surface temperature. The numerical coefficient $\beta_{1} \sim 0.1 / 0.2$ can be found in Golitsyn (1980) (note that $1 / 2 \beta_{1}$ is roughly equal to the numerical coefficient 5 in the approximate expression for the viscous boundary layer thickness $\delta_{*}$ in shear turbulence). The length scale $l_{\nu}$ in Eq. (1), which is determined by the viscosity and the acceleration due to gravity, is approximately equal to $3 \times 10^{-4} \mathrm{~m}$.

Equation (1) can easily be derived by estimating the basic terms in the Boussinesq-Oberbeck equations assuming that the velocity of motion is low (viscous thermal boundary layer). Here, the temperature drop $\delta T$ across the thermal boundary layer of thickness $\delta_{\mathrm{T}}$ in thickness is assumed to be known. Below, we use two assumptions (Gledzer et al., 2010). The first is that the viscous equations with low Reynolds numbers can be used within an about $1-\mathrm{cm}$ thick layer overlying a heated ground surface. The vertical length scale is then much less than the horizontal one. The second assumption is that velocity variations in this layer are determined by two independent factors, namely, by thermal convection in the layer and by fluctuations due to velocity shear in the outer (turbulent) region above the viscous layer, which affect the velocity field in the thermal boundary layer via the upper boundary condition at $z=\delta_{\mathrm{T}}$. From this, there appear two prescribed parameters $\delta T$ and $u_{*}$ which determine the flow in the layer and the layer thickness. Next, the equations are used to estimate the basic parameters of convective flows in the viscous thermal boundary layer. The main goal of these estimates is to show that the empirical dependencies in Sect. 2 do not contradict the fluid dynamic equations for thermally stratified flows. This especially concerns the fact that the exponents in the power law dependence on $\Delta C$ reverse their sign with increasing $u_{*}$.

\subsection{Basic equations and sublayers at the soil surface}

Let $w_{\mathrm{T}}$ be the vertical velocity at the thermal boundary layer height $z \approx \delta_{\mathrm{T}}$ and $\delta T$ be the difference between the temperatures at the underlying surface $(z=0)$ and the boundary layer height $\delta_{\mathrm{T}}$. Estimating the temperature deviation $T^{\prime}$ from $T_{0}$ Boussinesq-Oberbeck equations,

$$
\begin{aligned}
& \frac{\partial T^{\prime}}{\partial t}+(\boldsymbol{v} \nabla) T^{\prime}=\kappa_{\mathrm{T}} \Delta T^{\prime}, \\
& \frac{\partial w}{\partial t}+(\boldsymbol{v} \nabla) w=v \Delta w+g \frac{T^{\prime}}{T_{0}}-\frac{1}{\rho_{0}} \frac{\partial p^{\prime}}{\partial z},
\end{aligned}
$$



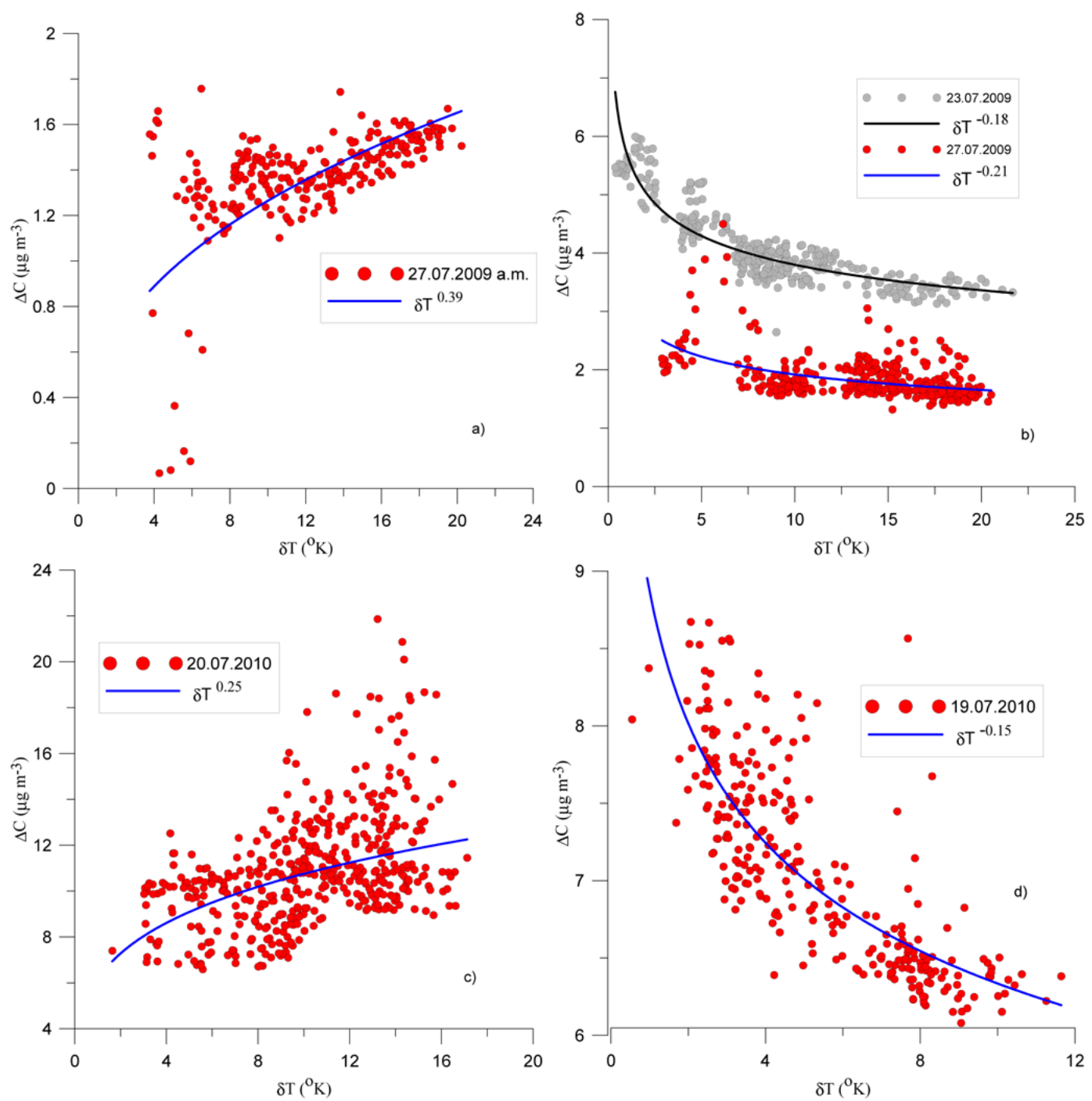

Fig. 7. Deviations of aerosol mass concentrations at a height $0.5 \mathrm{~m}$ from $1.5-\mathrm{m}$ (for 2009) $\left(\mu \mathrm{g} \mathrm{m}^{-3}\right.$ ) for particles $0.15-0.5 \mu \mathrm{m}$ as a function of the temperature difference $\delta T$ between the ground surface and $0.2 \mathrm{~m}$; (a) for 27 July a.m, 2009, the solid line denotes $\Delta C \sim \delta T^{0.39}$, (b) for 27 July p.m.., 2009, the solid line denotes $\Delta C \sim \delta T^{-0.21}$, for 23 July p.m. 2009, the solid line denotes $\Delta C \sim \delta T^{-0.18}$, (c) for 20 July 2010 , the solid line denotes $\Delta C \sim \delta T^{0.25}$, (d) for 19 July 2010, the solid line denotes $\Delta C \sim \delta T^{-0.15}$.

we have

$\frac{w_{\mathrm{T}} \delta T}{\delta_{\mathrm{T}}} \sim \kappa_{\mathrm{T}} \frac{\delta T}{\delta_{\mathrm{T}}^{2}}$,

$v \frac{w_{\mathrm{T}}}{\delta_{\mathrm{T}}^{2}} \sim g \frac{\delta T}{T_{0}}$,

which yields an estimate for $w_{\mathrm{T}}$ in terms of $\delta_{\mathrm{T}}$ and horizontal velocity $u_{\mathrm{T}}$ for disturbances with length scale $l$ :

$$
\begin{aligned}
& w_{\mathrm{T}} \sim \frac{\kappa_{\mathrm{T}}}{\delta_{\mathrm{T}}} \\
& \frac{u_{\mathrm{T}}}{l} \approx \frac{w_{\mathrm{T}}}{\delta_{\mathrm{T}}} .
\end{aligned}
$$

Combining Eqs. (4)-(7) creates Eq. (1) (without the numerical coefficient). Since the motion in a thin convective layer is quasi-horizontal, we assume that $l>\delta_{\mathrm{T}}$.

For the data discussed in this paper (as example, 28 and 29 July 2007), the characteristic vertical velocity $w_{\mathrm{T}}$ in the viscous thermal boundary layer (Eq. 6) ranges from 0.007 to $0.015 \mathrm{~m} \mathrm{~s}^{-1}$. The Stokes settling velocity is determined as (Shao, 2000)

$$
w_{\mathrm{t}}(d)=\left(\frac{4 \rho_{p} g d}{3 \rho C_{d}\left(R e_{\mathrm{t}}\right)}\right)^{1 / 2}
$$

$C_{d}\left(R e_{\mathrm{t}}\right)=\frac{24}{R e_{\mathrm{t}}}\left(1+0.15 R e_{\mathrm{t}}^{0.687}\right)$ 

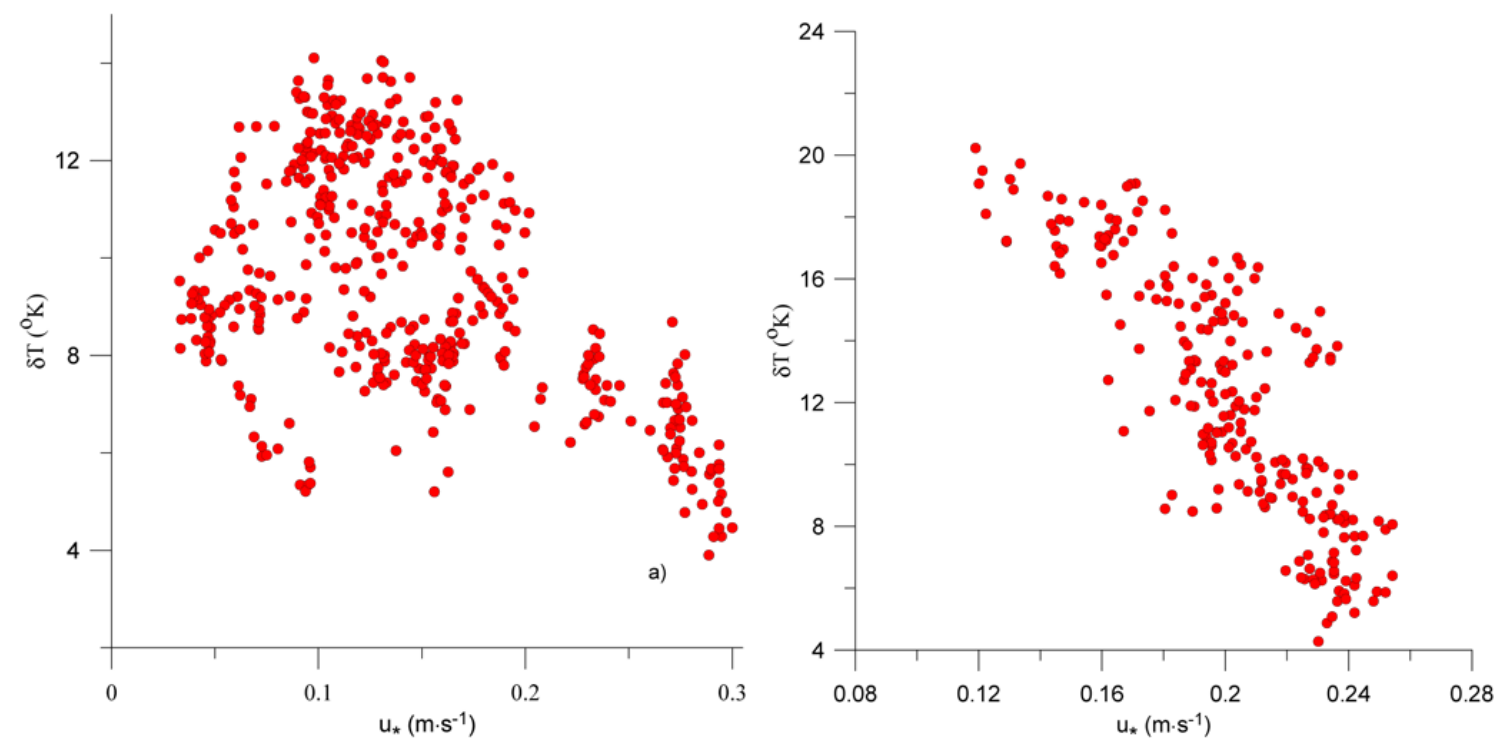

Fig. 8. Temperature drop $\delta T$ as a function of $u_{*}$ (a) for 28 July 2007, (b) for 27 July a.m. 2009.

where $R e_{\mathrm{t}}=w_{\mathrm{t}} d / \nu, \rho_{p}$ is the dust density, $\rho$ is the air density, $g$ is the gravity acceleration, $d$ is the size of particles. The size of dust particles with a density $2.6 \times 10^{3} \mathrm{~kg} \mathrm{~m}^{-3}$ having the setting velocity the same order with the specified above values $\left(0.007-0.015 \mathrm{~m} \mathrm{~s}^{-1}\right)$ would be $10 / 15 \mu \mathrm{m}$ in diameter. Thus, a fine aerosol detached and lifted from the surface is easily carried away into the atmosphere.

Now, formulas (Eq. 7) are extended to mean horizontal flows with vertical shear, which leads to the appearance of turbulent fluctuations proportional to $u_{*}$. Recall that velocity fluctuations with such an amplitude take place above the viscous sublayer, whose thickness $\delta_{*}$ is proportional to $v / u_{*}$. In the viscous sublayer, in the vicinity of the ground surface, the vertical and horizontal velocities fluctuations are estimated as linear functions for $z<\delta_{*}$

$w(z) \approx u_{*} \frac{z}{\delta_{*}}$

$u(z) \approx u_{*} \frac{z}{\delta_{*}}$

and for $z>\delta_{*}$

$w(z) \approx u_{*}$,

$u(z) \approx u_{*} \frac{z}{\delta_{*}}$.

\subsection{The thermal velocity for low and high friction velocities}

Assume that the vertical velocity $w_{\mathrm{T}}$ and horizontal velocity $\left.u_{\mathrm{T}} \equiv u\right|_{z=\delta_{\mathrm{T}}}$ at $z=\delta_{\mathrm{T}}$ can be evaluated as the sum of the velocities due to a shear flow without convection (Eqs. 811 ) and free convection (Eqs. 6, 7). If the thickness $\delta_{*}$ of the viscous sublayer is larger than the thickness $\delta_{\mathrm{T}}$ of the thermal layer $\delta_{\mathrm{T}}<\delta_{*}$ (i.e., $u_{*}$ is still sufficiently low), then

$$
\begin{aligned}
& w_{\mathrm{T}} \sim \frac{\kappa_{\mathrm{T}}}{\delta_{\mathrm{T}}}+u_{*} \frac{\delta_{\mathrm{T}}}{\delta_{*}}, \\
& u_{\mathrm{T}} \sim w_{\mathrm{T}} \frac{l}{\delta_{\mathrm{T}}}+u_{*} \frac{\delta_{\mathrm{T}}}{\delta_{*}},
\end{aligned}
$$

where the first terms in the right-hand side (Eqs. 12, 13) are caused by the thermal factors and the second terms by the friction velocity due to the shear in the mean horizontal velocity.

For a high friction velocity $u_{*}$, when $\delta_{\mathrm{T}}>\delta_{*}$, we have

$$
\begin{aligned}
& w_{\mathrm{T}} \sim \frac{\kappa_{\mathrm{T}}}{\delta_{\mathrm{T}}}+u_{*}, \\
& u_{\mathrm{T}} \sim w_{\mathrm{T}} \frac{l}{\delta_{\mathrm{T}}}+u_{*} \frac{\delta_{\mathrm{T}}}{\delta_{*}} .
\end{aligned}
$$

Using Eqs. (4), (5), and (12)-(15) for $w_{\mathrm{T}}$, we obtain for $\delta_{\mathrm{T}}$ and $u_{\mathrm{T}}$

$$
\begin{aligned}
& \delta_{\mathrm{T}} \sim d(q)\left(\frac{v^{2}}{g}\right)^{1 / 3} \operatorname{Pr}^{-1 / 3}\left(\frac{\delta T}{T_{0}}\right)^{-1 / 3}, \\
& u_{\mathrm{T}} \sim g l\left(\frac{\kappa_{\mathrm{T}}}{g v^{2}}\right)^{1 / 3}\left(\frac{\delta T}{T_{0}}\right)^{2 / 3} d(q)\left(1+\frac{u_{*}^{2}}{g l}\left(\frac{\delta T}{T_{0}}\right)^{-1}\right),
\end{aligned}
$$

where $q$ is the dimensionless friction velocity

$q=\frac{u_{*}}{(g \nu)^{1 / 3}} \operatorname{Pr}^{1 / 6}\left(\frac{\delta T}{T_{0}}\right)^{-1 / 3}, \operatorname{Pr}=\frac{\nu}{\kappa_{\mathrm{T}}}$.

For $d$ and $q$ we have the equations (see details in Gledzer et al., 2010)

$$
\begin{aligned}
& d^{3}-q^{2} d^{2}-1=0, q d<\operatorname{Pr}^{1 / 2}, \\
& d^{3}-\operatorname{Pr}^{1 / 2} q d-1=0, q d>\operatorname{Pr}^{1 / 2} .
\end{aligned}
$$


The investigation of these equations gives the following asymptotics for $u_{\mathrm{T}}$ : for $u_{*} \sim u_{1}=(g \nu)^{1 / 3}\left(\delta T / T_{0}\right)^{1 / 3} \sim$ $0.02 / 0.05 \mathrm{~m} \mathrm{~s}^{-1}$

$u_{\mathrm{T}}=\left(\frac{\delta T}{T_{0}}\right)^{2 / 3} C_{1}\left(l, v, \kappa_{\mathrm{T}}\right), C_{1} \approx g l \operatorname{Pr}^{-1 / 3}(g \nu)^{-1 / 3}$,

for moderate values of $u_{*} \sim u_{2}=(g l)^{1 / 2}\left(\delta T / T_{0}\right)^{1 / 2} \sim$ $0.2 \mathrm{~m} \mathrm{~s}^{-1}$ (for $l \sim 0.05-0.1 \mathrm{~m}, \delta T / T_{0} \sim 0.1$ )

$u_{\mathrm{T}}=\left(\frac{\delta T}{T_{0}}\right)^{1 / 2} u_{*}^{1 / 2} C_{2}\left(l, v, \kappa_{\mathrm{T}}\right), C_{2} \approx g l \operatorname{Pr}^{-1 / 4}(g v)^{-1 / 2}$,

for large values of $u_{*} \gg u_{2}$

$u_{\mathrm{T}}=\left(\frac{\delta T}{T_{0}}\right)^{-1 / 2} u_{*}^{5 / 2} C_{3}\left(v, \kappa_{\mathrm{T}}\right), C_{3} \approx(g v)^{-1 / 2} \mathrm{Pr}^{-1 / 6}$.

The dimensional factors $C_{1}, C_{2}, C_{3}$ in Eqs. (18)-(20) are determined only by physical constants and the horizontal length scale $l$ of velocity perturbations. Relations (18) and (19) for $u_{\mathrm{T}}$ regarded as a function of $\delta T$ show that for small and moderate values of $u_{*}$, the exponent $\alpha$ in $u_{\mathrm{T}} \sim(\delta T)^{\alpha}$ varies slightly in the range $1 / 2<\alpha<2 / 3$. However, for high $u_{*}$, the horizontal velocity amplitude at the upper boundary of thermal layer decreases with growing $\delta T, u_{\mathrm{T}} \sim(\delta T)^{-1 / 2}$. The sign of $\alpha$ is changed for $u_{*} \approx 0.3 \mathrm{~m} \mathrm{~s}^{-1}$.

\subsection{Dynamics of mass concentrations}

These dependencies are used to estimate the aerosol amount within the surface boundary layer in a Caspian desert. The basic external parameters include $u_{*}$ (which is determined from measured horizontal-velocity profiles) and the temperature difference $\delta T$ in the viscous thermal boundary layer. Velocity and temperature are rather difficult to measure at the height of the thermal boundary layer $\delta_{\mathrm{T}}$, which is on the order of $1 \mathrm{~cm}$. In fact, we can only determine the temperature difference $\delta T$ between the sand surface and the height $0.2 \mathrm{~m}$ and estimate $u_{*}$ from measured profiles of the horizontal velocity. This value of $\delta T$ is a good estimate of temperature drop in a viscous thermal boundary layer, since temperature variations above this layer are relatively weak.

As was mentioned in the Introduction, our basic assumption is that the difference between the mass concentrations $\Delta C$ at two levels (at the surface and above the thermal boundary layer) is proportional to the velocity amplitude $u_{\mathrm{T}}$ at the height of the thermal boundary layer $\delta_{\mathrm{T}}$ :

$\Delta C \sim u_{\mathrm{T}}-u_{\mathrm{T}_{\mathrm{cr}}}$.

The two quantities $\delta_{\mathrm{T}}, u_{\mathrm{T}}$ are determined from measured $\delta T$ and $u_{*}$ according to Eqs. (16)-(20). The proportionality of the velocity in Eq. (21) implies that, on the one hand, aerosol resuspension from the upper soil layer is enhanced with increasing $u_{\mathrm{T}}$. On the other hand, a high horizontal velocity near the underlying surface impedes the settling of previously lifted aerosol particles.

Some substantiations of the Eq. (21) can be gained from a diffusion equation for a fine dispersed dust in an viscousthermal layer of air immediately adjoining a surface of soil,

$\frac{\partial C}{\partial t}+\frac{\partial w(z) C}{\partial z}=\kappa_{c} \frac{\partial^{2} C}{\partial z^{2}}, z>0 ; C=C_{0}, z=0$.

In this equation, the horizontal coordinates are neglected, because the concentration $C$ slightly depends on them; $\kappa_{c}$ is the kinematic diffusion of dust under consideration. Equation (22) implies that the dust is fine dispersed. So, this allow us to be restricted to an approximation with the written out terms of diffusion type.

We suppose that the soil is a source of dust with the surface concentration $C_{0}$. Firstly we consider the case of relative small friction velocity $u_{*}$. Under these conditions, $\delta_{\mathrm{T}}<\delta_{*}$, so the second addend in the right-hand part of Eq. (15) for $u_{\mathrm{T}}$ does not exceed the convective contribution $\frac{w_{\mathrm{T}} l}{\delta_{\mathrm{T}}}$. Then, vertical velocity $w(z)$ in Eq. (22) can be approximated by linear function

$w(z) \approx \frac{w_{\mathrm{T}}}{\delta_{\mathrm{T}}} \cdot z \sim \frac{u_{\mathrm{T}}}{l} \cdot z$.

From Eqs. (22), (23) under the stationary conditions we obtain

$\frac{\partial f_{C}}{\partial z}=0, f_{C}=C \frac{u_{\mathrm{T}}}{l} z-\kappa_{c} \frac{\partial C}{\partial z}$.

Here $f_{C}$ is the dust flux from the surface. An Eq. (24) gives the solution

$$
\begin{aligned}
C(z) & =\left(C_{0}-\frac{f_{C}}{\kappa_{c}} \int_{0}^{z} \exp \left(-\frac{u_{\mathrm{T}} \zeta^{2}}{2 l \kappa_{c}}\right) d \zeta\right) \exp \left(-\frac{u_{\mathrm{T}} z^{2}}{2 l \kappa_{c}}\right) \\
& \approx C_{0}-z \frac{f_{C}}{\kappa_{c}}+\left(C_{0}-z \frac{2 f_{C}}{3 \kappa_{c}}\right) \frac{u_{\mathrm{T}} z^{2}}{2 l \kappa_{c}} .
\end{aligned}
$$

Here due to the smallness of the height $z$, we consider only the first terms of the exponent decomposition, supposing that the diffusion coefficient $\kappa_{c}$ is sufficiently large for the thickness of a diffusion layer to be larger than those of the thermal $\left(\delta_{\mathrm{T}}\right)$ and viscous $\left(\delta_{*}\right)$ layers. For fixed $z=z_{0} \sim \delta_{*}>\delta_{\mathrm{T}}$ we have a condition of turbulent mixing. Therefore, the concentration $C\left(z_{0}\right)$ is a boundary for processes in this layer. The difference $\Delta C$ between $C\left(z_{0}\right)$ and background $C(\infty)$ (for the results presented in the previous section $C(2.0)$ or $C(1.5))$ can be written as

$$
\begin{aligned}
& \Delta C=\gamma\left(u_{\mathrm{T}}-u_{\mathrm{T}_{\mathrm{cr}}}\right), \\
& \gamma=\left(C_{0}-z \frac{2 f_{C}}{3 \kappa_{c}}\right) \frac{z_{0}^{2}}{2 l \kappa_{c}}, \\
& \gamma u_{\mathrm{T}_{\mathrm{cr}}}=C(\infty)-\left(C_{0}-z \frac{f_{C}}{\kappa_{c}}\right) .
\end{aligned}
$$


This difference can be considered as an approximation of the measurement results given in the previous paragraph.

In the case of large values of friction velocity $u_{*}$ when $\delta_{\mathrm{T}}>\delta_{*}$ and the viscous layer directly adjoins the soil, Eq. (22) can be considered in a thermal layer $\delta_{*}<z<\delta_{\mathrm{T}}$ with $C=C_{0}$ at the external boundary of the viscous layer $z=z_{*}=\delta_{*}$. In the upper part of the thermal layer, we have $w(z) \approx u_{*}$ (see Eq. 15), so

$f_{C}=u_{*} C-\kappa_{c} \frac{\partial C}{\partial z}$.

As a result at $z_{0}=\delta_{\mathrm{T}}$ we will obtain the formula similar to Eq. (25):

$C\left(z_{0}\right) \approx C_{0}-z_{0} \frac{f_{C}}{\kappa_{c}}+\left(C_{0}-z_{0} \frac{f_{C}}{2 \kappa_{c}}\right) \frac{u_{\mathrm{T}} \delta_{*}}{\kappa_{c}}$,

where, for the $u_{\mathrm{T}}$ approximation, the second addend in the right-hand part of Eq. (15) was used. From here follows the relationship for $\Delta C$ (Eq. 26), where

$\gamma=\left(C_{0}-z_{0} \frac{f_{C}}{2 \kappa_{c}}\right) \frac{\delta_{*}}{\kappa_{c}}, \gamma u_{\mathrm{T}_{\mathrm{cr}}}=C(\infty)-\left(C_{0}-z_{0} \frac{f_{C}}{\kappa_{c}}\right)$.

In view of Eq. (21) with $u_{\mathrm{T}} \gg u_{\mathrm{T}_{\text {cr }}}$, Eqs. (18), (19), (20) for $u_{\mathrm{T}}$ imply that, for small and moderate values of $u_{*}$, the exponent $\alpha$ in

$\Delta C \sim(\delta T)^{\alpha}$

ranges between $1 / 2$ and $2 / 3$. For large $u_{*}$ the aerosol mass concentration $\Delta C$ decreases like $(\delta T)^{-1 / 2}$ with increasing $\delta T$. This behavior of $\Delta C$ is shown in Figs. 4, 6, 7 with $\alpha=$ 0.58 (Fig. 4a), 0.52 (Fig. 4b), 0.33 (Fig. 4c), 0.24 (Fig. 4d), -0.5 (Fig. 6a, 30 July 2007), -0.35 (Fig. 6a, 31 July 2007), -0.35 (Fig. 6c), 0.39 (Fig. 7a), $-0.21,-0.18$ (Fig. 7b), 0.25 (Fig. 7c), -0.15 (Fig. 7d).

\subsection{The heat flux as the external parameter}

In Obukhov (1971); Monin and Yaglom (1971); Lumley and Panofsky (1964) the basic parameter determining convection is the turbulent heat flux rather than $\delta T$. For comparison purposes, the formulas derived above can be rewritten in terms of a given heat flux $f$ from the underlying surface. Simultaneously, the flow parameters in the thermal boundary layer can be estimated as functions of $u_{*}$, since $f$ exhibits smaller variations than $\delta T$ when the ground surface is heated to its maximum temperature. Specifically, $f$ is determined only by insolation and the soil properties, while $\delta T$ depends on $f$ and the wind near the surface.

To proceed from the temperature difference to the heat flux, the temperature equation in Eq. (2) is integrated over the height $z$ from 0 to $\delta_{\mathrm{T}}$, assuming that the basic temperature variations occur in the layer $0<z<\delta_{\mathrm{T}}$ and, for $z \sim \delta_{\mathrm{T}}$, the lapse rate is much less than that at the surface $z=0$. Then, after integrating, the term $\partial w T^{\prime} / \partial z$ gives the estimate $w_{\mathrm{T}} \delta T$, while the term $\kappa_{\mathrm{T}}\left(\partial^{2} T^{\prime} / \partial z^{2}\right)$ leads to $-\kappa_{\mathrm{T}} \partial T^{\prime} /\left.\partial z\right|_{z=0}=$ $f / \rho c_{p}$ :

$w_{\mathrm{T}} \delta T \approx \frac{f}{\rho c_{p}}$,

where $f$ is the heat flux from the surface $z=0$.

Combined with Eqs. (4), (5), (12)-(15), this relation yields the following estimates for $\delta T$ and $\delta_{\mathrm{T}}$ in terms of $f$ and $u_{*}$ :

$\delta_{\mathrm{T}} \approx h\left(\frac{\delta T}{T_{0}}\right)^{-1}, h=\left(v f / g \rho c_{p} T_{0}\right)^{1 / 2}$,

$\frac{\delta T}{T_{0}} \approx\left(\frac{g h^{3}}{v \kappa_{\mathrm{T}}}\right)^{1 / 2}\left(1-\frac{u_{*}^{2}}{g h}\right)^{1 / 2}$,

$\frac{\delta T}{T_{0}} \approx \frac{h u_{*}}{2 \kappa_{\mathrm{T}}}\left[\left(1+\frac{4 g h}{P r u_{*}^{2}}\right)^{1 / 2}-1\right]$.

where the first estimate (Eq. 33) is valid for $u_{*}^{2} / g h \leq$ $\operatorname{Pr} /(1+P r)$, and second estimate (Eq. 34) is valid for $u_{*}^{2} / g h \geq \operatorname{Pr} /(1+\operatorname{Pr})$.

Here, $h$ is the length scale (Eq. 32) determined by the heat influx and viscosity.

In view of Eq. (32) and $u_{*}=0$, relation in Eq. (33) gives the well-known dependence $\delta T \sim f^{3 / 4}$ (see Golitsyn, 1980). It also follows from Eq. (34) that $\delta T$ decreases with increasing $u_{*}$. For high friction velocities $\left(u_{*}^{2} \gg g h\right)$, we have

$\frac{\delta T}{T_{0}} \approx \frac{g h^{2}}{v} \frac{1}{u_{*}}=\frac{f}{u_{*} T_{0} \rho c_{p}}=\frac{u_{f}}{u_{*}}$,

where $u_{f}=f / \rho c_{p} T_{0}$ is the heat transfer rate introduced by A. M. Obukhov Obukhov (1971). The thermal boundary layer thickness $\delta_{\mathrm{T}}$ is then determined by the formula

$\delta_{\mathrm{T}} \approx u_{*} \frac{v}{g h}=h \frac{u_{*}}{u_{f}}$.

Since the right-hand side of Eq. (35) does not involve the viscosity or thermal diffusivity, Eq. (35) gives the wellknown temperature scale for the atmospheric surface layer (the only quantity of the dimension of temperature can be made up of $\left.u_{*}, f / c_{p} \rho\right)$. Note that $h$ is small; for example, for the heat flux $f=500 \mathrm{~W} \mathrm{~m}^{-2}=5 \times 10^{5} \mathrm{~g} \mathrm{~s}^{-3}$ (see the Introduction), $h \sim 10^{-4} \mathrm{~m}$.

It follows from Eq. (34) that $\delta T$ decreases with an increase in $u_{*}$, which is also seen from the measurement data (Fig. 8). In this case, according to estimates from Eqs. (16)-(18), (21), $\Delta C$ decreases. It is easily seen in Fig. $9 \mathrm{a}-\mathrm{c}$ for $\Delta \mathrm{C}$ measured at moderate values of $u_{*}$. In fact, this means that convective aerosol resuspension (emission) from the soil can be more effective almost in the absence of wind (low friction velocities, $u_{*}<0.08-0.2 \mathrm{~m} \mathrm{~s}^{-1}$ in Fig. 9a-c) than in moderate wind (when $0.1 \mathrm{~m} \mathrm{~s}^{-1}<u_{*}<0.2-0.3 \mathrm{~m} \mathrm{~s}^{-1}$, Fig. 9d). For these latter values of $u_{*}$ the $\Delta C$ deviations are nearly 

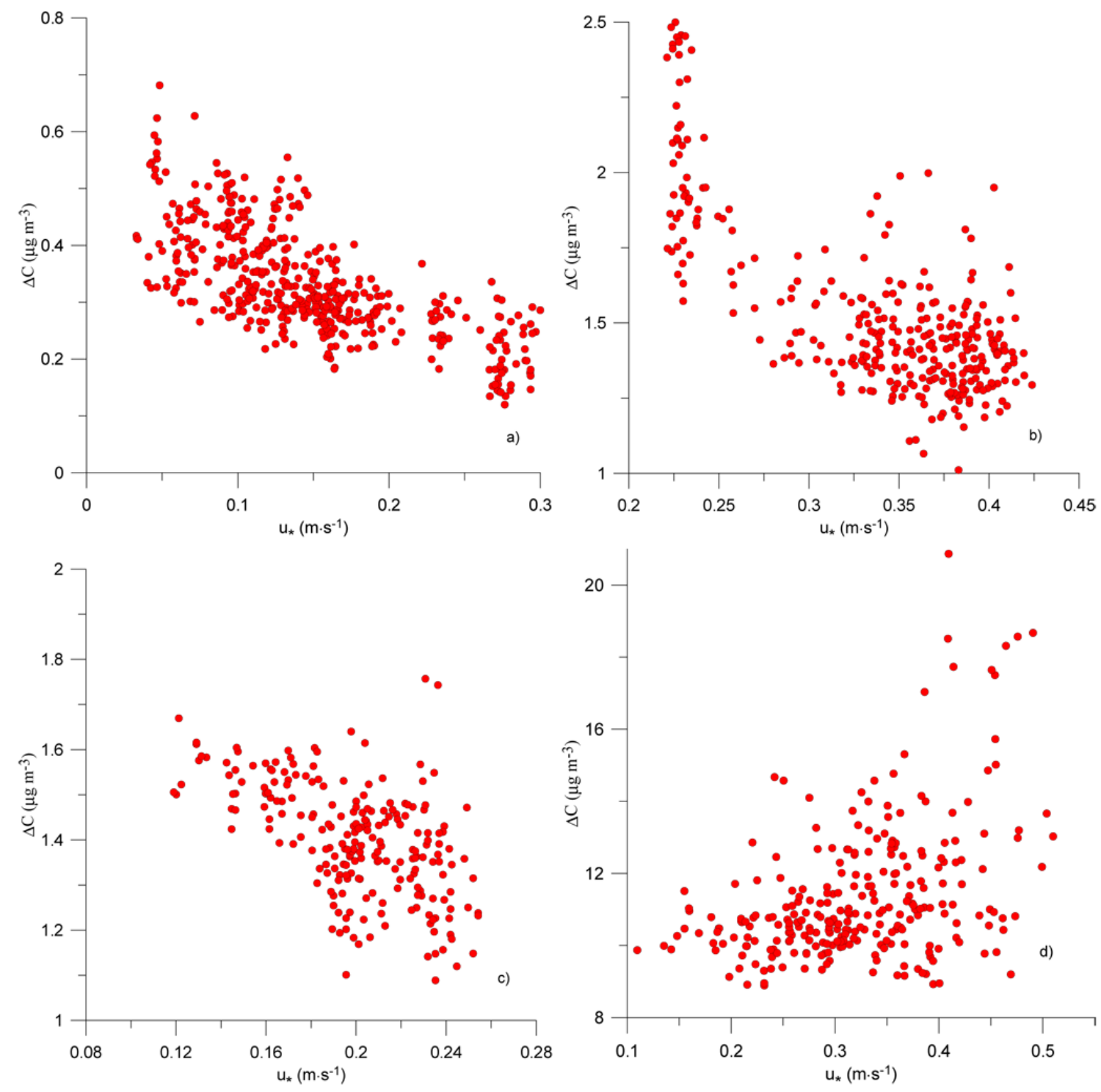

Fig. 9. Deviations of the aerosol mass concentration at a height of $0.5 \mathrm{~m}$ from its background value for $2 \mathrm{~m}(2007)$ or $1.5 \mathrm{~m} \mathrm{(2009)}\left(\mu \mathrm{g} \mathrm{m}{ }^{-3}\right.$ ) for particles $0.15-0.5 \mu \mathrm{m}$ in size as a function of the friction velocity $u_{*}$ : (a) 28 July 2007, (b) 30 July 2007, (c) 27 July a.m. 2009, (d) 20 July 2010 .

constant, which follows from the estimates for $\delta T$ (Eq. 35) and for $u_{\mathrm{T}}$ (Eq. 19).

At the end of this section it should be noted that, according to Eqs. (18)-(20), the linearity in Eq. (21) with respect to $u_{\mathrm{T}}$ does not mean linearity with respect to $u_{*}$. Moreover, for high $u_{*}$ (see Eq. 20), the mass concentration $\Delta C$ is proportional to $u_{*}^{5 / 2}$ for fixed $\delta T$ and $\Delta C \sim u_{*}^{3}$, if $f$ is given: $\left(\frac{\delta T}{T_{0}}\right)^{-1 / 2} \sim u_{*}^{1 / 2}$ (see Eq. 35). The flux of fine dispersed particles from the soil surface $z=0$ is equal to $f_{C}=-\left.\kappa_{c} \frac{\mathrm{d} C}{\mathrm{~d} z}\right|_{z=0}$ (see Eq. 24). To estimate this latter expression, we can assume that $f_{C} \sim \kappa_{c} \frac{|\Delta C|}{\delta z}$, where $\delta z$ is the difference of the measurements levels. So, for the given heat flux $f$ we obtain Bagnold's dependence $u_{*}^{3}$. This circumstance can serve as an additional argument for assumption (Eq. 21), despite its obvious simplicity. For fine dispersed aerosol particles, the dependence $\sim u_{*}^{3}$ was obtained also under laboratory conditions (Loosmore and Hunt, 2000).

\section{Conclusions}

The basic assumption in this work is that fine aerosol resuspension from the soil is proportional to the horizontal air velocity $u_{\mathrm{T}}$ at the height of the thermal boundary layer. In addition to the obvious simplicity of this hypothesis, another supporting argument is that it implies Bagnold's law $u_{*}^{3}$ for relatively high friction velocities: an increase in $u_{\mathrm{T}}$ leads to 
resuspension of not only fine aerosol but also coarse soil particles that satisfy this law. However, it should be noted that the last empirical law holds when $u_{*}$ is higher than the threshold value $\sim 0.4-0.5 \mathrm{~m} \mathrm{~s}^{-1}$. The thermal factors then become not very significant, and sand and aerosol are carried away by strong turbulent velocity fluctuations ensuring the rolling and saltation of numerous particles at the ground surface. In this work, primary attention was given to the thermal factors at relatively low friction velocities associated with the mean wind shear.

The results of measurements show that the fine aerosol in the region under consideration significantly contributes to the total amount of aerosol in the atmospheric surface layer under the conditions of light winds. Also, the difference between the aerosol concentrations at two near-ground levels depends both on the temperature difference $\delta T$ in the viscous thermal sublayer and on the friction velocity $u_{*}$ in the surface turbulent mixing layer. The use of concentration differences $\Delta C$ yields more clear dependencies than the use of the concentrations $C(z)$ at near-ground levels, since the latter can be more variable and depend on conditions preceding the measurements. This can be seen in Fig. 5 .

For low and moderate friction velocity $u_{*}$, Eqs. (18) and (19) and Figs. 4, 7a, 7c show that, as $\delta T$ grows, $u_{\mathrm{T}}$ increases with positive exponent $\alpha$ (ranging from $1 / 2$ to $2 / 3$ in the model of convection). For high $u_{*}$, as $\delta T$ grows, $u_{\mathrm{T}}$ decreases with negative exponent $\alpha$ (Figs. 6, 7b, 7d).

The estimates of the model Eqs. (16), (18)-(20), (33)-(34) show that the convective resuspension of fine aerosols under windless or light-wind conditions can be more effective than under moderate winds. This is demonstrated in Fig. 9a-c for several days of measurements.

Of course, for stronger winds $\left(u_{*}>0.3-0.4 \mathrm{~m} \mathrm{~s}^{-1}\right.$, Fig. 9d), the $u_{*}$ dependence of $\Delta C$ changes. However, as was mentioned at the beginning of the Introduction, for this case, the basic mechanism for aerosol resuspension or emission from the soil is the rolling and saltation of large particles pulled out of the viscous boundary layer $\delta_{*}$ due to wind forcing.

Thus, as expected, the dynamics of air and aerosol transport in the adjacent layers with different physical and hydrodynamic properties represents a complicated problem requiring substantially different approaches to its solution.

Though the intensity of dust resuspension mechanism considered in this paper is weaker than saltation, nevertheless, it may occur almost every day during the hot season in arid lands. At the same time, extreme events similar to dust storms or strong winds are less frequent. Accordingly, a convective resuspension of submicron aerosol in the surface layer can make a noticeable contribution to global dust recirculation.

Acknowledgements. This work was initiated $15 \mathrm{yr}$ ago by I. G. Granberg and V. M. Ponomarev. The authors are grateful to A. A. Khapaev, V. K. Bandin, I. A. Bouchnev, B. A. Khartskhaev,
S. A. Kosyan, V. A. Lebedev, F. A. Pogarskii, I. A. Repina and B. V. Zoudin for their help in carrying out the field measurements.

The authors are grateful to G. S. Golitsyn for his interest in this work and helpful remarks. This work was supported by the Russian Foundation for Basic Research (project no. 10-05-01110).

We would like to thank two anonymous referees for their useful comments.

Edited by: M. Kulmala

\section{References}

Bagnold, R. A.: The Physics of Blown Sand and Desert Dunes, Methuen, New York, 265 pp., 1941.

Barenblatt, G. I. and Golitsyn, G. S.: Local structure of mature dust storms, J. Atmos. Sci., 31, 1917-1933, 1974.

Borrmann, S. and Jaenicke, R.: Wind tunnel experiments on the resuspension of sub-micrometer particles from a sand surface, Atmos. Environ., 21, 1891-1898, 1987.

Cakmur, R. V., Miller, R. L., and Torres, O.: Incorporating the effect of small-scale circulations upon dust emission in an atmospheric general circulation model, J. Geophys. Res., 109, D07201, doi:10.1029/2003JD004067, 2004.

Darmenova, K., Sokolik, I. N., Shao, Y., Marticorena, B., and Bergametti, G.: Development of a physically based dust emission module within the Weather Research and Forecasting (WRF) model: Assessment of dust emission parameterizations and input parameters for source regions in Central and East Asia, J. Geophys. Res., 114, D14201, doi:10.1029/2008JD011236, 2009.

Foken, T. H.: The molecular temperature boundary layer of the atmosphere over various surfaces, Arch.Met Geoph.Biokl., Ser.A, 27, 59-67, 1978.

Foken, T. H.: Micrometeorology, Springer-Verlag Berlin Heidelberg, 306 pp., 2008.

Gillette, D. A. and Sinclair, P. C.: Estimation of suspension of alkaline material by dust devils in the United States, Atmos. Environ., 24A, 1135-1142, 1990.

Gillette, D. A., Fryear, D. W., Gill, T. E., Ley, T., Cahill, T. A., and Gearhart, E. A.: Relation of vertical flux of particles smaller than $10 \mu \mathrm{m}$ to total aeolian horizontal mass flux at Owens Lake, J. Geophys. Res., 102, 26009-26015, 1997.

Gillette, D. A., Lawson Jr., R. E., and Thompson, R. S. A.: “test of concept" comparison of aerodynamic and mechanical resuspension mechanizms for particles deposited on field rye grass. Part 1. Relative particle flux rates, Atmos. Environ., 38, 4789-4797, 2004.

Gledzer, E. B., Granberg, I. G., and Chkhetiani, O. G.: Air dynamics near the soil surface and convective emission of aerosol, Izvestiya, Atmos. Ocean. Phys., 46, 29-40, 2010.

Golitsyn, G. S.: Simple theoretical and experimental study of convection with some geophysical applications and analogies, J. Fluid Mech., 95, 567-608, 1980.

Golitsyn, G. S. and Smirnov, V. V. (Eds.): Joint Soviet-American experiment on arid aerosol, St. Petersburg, Hydrometeoizdat, 220 pp., 1993.

Golitsyn, G. S., Granberg, I. G., Aloyan, A. E., Andronova, A. V., Gorchakov, G. I., Ponomarev, V. M., and Shishkov, P. O.: Study 
of emissions and transport of dust aerosol in Kalmykia Black Lands, J. Aerosol. Sci., 28, Suppl. 1, S725-S726, 1997.

Golitsyn, G. S., Granberg, I. G., Andronova, A. V., Ponomarev, V. M., Zilitinkevich, S. S., Smirnov, V. V., and Yablokov, M. Y.: Investigation of boundary layer fine structure in arid regions, Water Air Soil Pollut., Focus, 3, 245-257, 2003.

Gorchakov, G. I., Koprov, B. M., and Shukurov, K. A.: Arid aerosol transport by vortices, Izvestia, Atmos. Ocean. Phys., 39, 596608, 2003.

Greeley, R. and Iversen, J. D.: Wind as a geological process on Earth, Mars, Venus and Titan, Cambridge University Press, New York, 333 pp., 1985.

IPCC IV: Climate Change 2007: The Physical Science Basis, Cambridge Univ. Press, New York, 940 pp., 2007.

Junge, C.: Air chemistry and radioactivity, Academic Press, New York, 382 pp., 1963.

Kandler, K., Schütz, L., Deutscher, C., Ebert, M., Hofmann, H., Jäckel, S., Jaenicke, R., Knippertz, P., Lieke, K., Massling, A., Petzold, A., Schladitz, A., Weinzierl, B., Wiedensohler, A., Zorn, S., and Weinbruch, S.: Size distribution, mass concentration, chemical and mineralogical composition and derived optical parameters of the boundary layer aerosol at Tinfou, Morocco, during SAMUM 2006, Tellus, 61B, 32-50, doi:10.1111/j.16000889.2008.00385.x, 2009.

Klose, M. and Shao, Y.: Stochastic parameterization of dust emission and application to convective atmospheric conditions, Atmos. Chem. Phys. Discuss., 12, 3263-3293, doi:10.5194/acpd12-3263-2012, 2012.

Kok, J. F. and Renno, N. O.: Enhancement of the emission of mineral dust aerosols by electric forces, Geophys. Res. Lett., 33, L19S10, doi:10.1029/2006GL026284, 2006.

Kok, J. F. and Renno, N. O.: A comprehensive numerical model of steady state saltation (COMSALT), J. Geophys. Res., 114, D17204, doi:10.1029/2009JD011702, 2009.

Kozlov, A. S., Ankilov, A. N., Baklanov, A. M., Vlasenko, A. L., Eremenko, S. I., and Malyshkin, S. B.: Investigation of mechanical processes of submicron aerosol formation, Atmos. Ocean. Opt. C, 13, 617-619, 2000.

Larsen, S. E., Jorgensen, H. E., Landberg, L., and Tillman, J. E.: Aspects of the atmospheric surface layers on Mars and Earth, Bound.-Lay. Meteorol., 105, 451-470, 2002.

Lumley, J. L. and Panofsky, H. A.: The Structure of Atmospheric Turbulence, Interscience Publishers, New York, 239 pp., 1964.

Loosmore, G. A. and Hunt, J. R.: Dust resuspension without saltation, J. Geophys.Res, 105, 20663-20671, 2000.
Marsham, J. H., Parker, D. J., Grams, C. M., Johnson, B. T., Grey, W. M. F., and Ross, A. N.: Observations of mesoscale and boundary-layer scale circulations affecting dust transport and uplift over the Sahara, Atmos. Chem. Phys., 8, 6979-6993, doi:10.5194/acp-8-6979-2008, 2008.

Monin, A. S. and Yaglom, A. M.: Statistical Fluid Mechanics. V.1, MIT Press, Cambridge, London, 769 pp., 1971.

Mikami, M., Aoki, T., Ishizuka, M., Yabuki, S., Yamada, Y., Gao, W., and Zeng, F.: Observation of Number Concentration of Desert Aerosols in the South of the Taklimakan Desert, China, J. Met. Soc. Jap., 83A, 31-43, 2005.

Obukhov, A. M.: Turbulence in an atmosphere with a non-uniform temperature, Bound.-Lay. Meteorol., 2, 7-29, 1971.

Ponomarev, V. M.: Micro-scale modelling of pollution dispersion in atmospheric boundary layer, Syst. Anal. Model. Sim., 30, 39-44, 1998.

Shao, Y.: Physics and modelling of wind erosion, Kluwer Academic, Boston, 452 pp., 2000.

Takemi, T., Yasui, M., Zhou, J., and Lichao Liu, L.: Role of boundary layer and cumulus convection on dust emission and transport over a midlatitude desert area, J. Geophys. Res., 111, D11203, doi:10.1029/2005JD006666, 2006.

Wang, X., Huang, J., Zhang, R., Chen, B., and Bi, J.: Surface measurements of aerosol properties over northwest China during ARM China 2008 deployment, J. Geophys. Res., 115, D00K27, doi:10.1029/2009JD013467, 2010.

Weinzierl, B., Petzold, A., Esselborn, M., Wirth, M., Rasp, K., Kandler, K., Schütz, L., Koepke, P., and Fiebig, M.: Airborne measurements of dust layer properties, particle size distribution and mixing state of Saharan dust during SAMUM 2006, Tellus B, 61, 96-117, doi:10.1111/j.1600-0889.2008.00392.x, 2009.

Yablokov, M. Y. and Andronova, A. V.: A model of takeoff processes of desert sand aerosols in windless conditions, J. Aerosol. Sci., 28, Suppl. 1, S563-S564, 1997.

Zhulanov, Yu. V., Zagaynov, Lushnikov, A. A., Lyubovtseva, Yu. S., Nevskiy, I. A., and Stulov, L. D.: Highly dispersed submicron atmospheric aerosols of the arid zone, Izvestiya, Atmos. Ocean. Phys., 22, 29-40, 1986.

Zhou, Y., Guo, X., and Zheng, X. J.: Experimental measurements of wind-sand flux and sand transport for naturally mixed sands, Phys. Rev. E, 66, 021305, doi:10.1103/PhysRevE.66.021305, 2002. 